\title{
Review \\ The Role of Methionine Residues in the Regulation of Liquid-Liquid Phase Separation
}

\author{
Juan Carlos Aledo
}

check for

updates

Citation: Aledo, J.C. The Role of Methionine Residues in the Regulation of Liquid-Liquid Phase Separation. Biomolecules 2021, 11, 1248. https://doi.org/10.3390 /biom11081248

Academic Editor: Brigita Urbanc

Received: 24 July 2021

Accepted: 18 August 2021

Published: 21 August 2021

Publisher's Note: MDPI stays neutral with regard to jurisdictional claims in published maps and institutional affiliations.

Copyright: (C) 2021 by the author. Licensee MDPI, Basel, Switzerland. This article is an open access article distributed under the terms and conditions of the Creative Commons Attribution (CC BY) license (https:/ / creativecommons.org/licenses/by/ $4.0 /)$.
Departamento de Biología Molecular y Bioquímica, Facultad de Ciencias, Universidad de Málaga, 29071 Málaga, Spain; caledo@uma.es

\begin{abstract}
Membraneless organelles are non-stoichiometric supramolecular structures in the micron scale. These structures can be quickly assembled/disassembled in a regulated fashion in response to specific stimuli. Membraneless organelles contribute to the spatiotemporal compartmentalization of the cell, and they are involved in diverse cellular processes often, but not exclusively, related to RNA metabolism. Liquid-liquid phase separation, a reversible event involving demixing into two distinct liquid phases, provides a physical framework to gain insights concerning the molecular forces underlying the process and how they can be tuned according to the cellular needs. Proteins able to undergo phase separation usually present a modular architecture, which favors a multivalencydriven demixing. We discuss the role of low complexity regions in establishing networks of intraand intermolecular interactions that collectively control the phase regime. Post-translational modifications of the residues present in these domains provide a convenient strategy to reshape the residue-residue interaction networks that determine the dynamics of phase separation. Focus will be placed on those proteins with low complexity domains exhibiting a biased composition towards the amino acid methionine and the prominent role that reversible methionine sulfoxidation plays in the assembly/disassembly of biomolecular condensates.
\end{abstract}

Keywords: methionine sulfoxide; biomolecular condensate; stress granule; ataxin-2; TDP43; Pab1

\section{Introduction}

Cells need to organize and coordinate their biochemical processes both in space and time to adapt to their changing environments. In this regard, compartmentalization has long been recognized as an important strategy of cellular regulation [1,2]. Even the simplest eukaryotic cell exhibits an intricate endomembrane system that defines compartments, also known as organelles, in which specific biological processes take place [3]. Using semipermeable membranes to divide the cellular space helps to separate chemically heterogeneous environments, providing optimal conditions for specific sets of reactions and avoiding potential interferences between biological processes that, in this way, can take place simultaneously. This is also true for organelles that are not part of the endomembrane system, such as mitochondria, plastids, and peroxisomes. Nevertheless, despite the advantages of a membranous system of compartmentalization, this regulatory principle is not a universal feature of life. Although some bacteria possess compartments bound by either a lipid bilayer (such as magnetosomes and thylakoids) or a lipid monolayer (lipid bodies) [4], the use of a proper endomembrane system to organize cellular functions is limited to eukaryotic cells.

In addition to membranous organelles, a new level of compartmentalization has gained conspicuous relevance in recent years, namely the formation of biomolecular condensates, which can be organized into specific but non-stoichiometric supramolecular structures that are generally referred to as membraneless organelles (MLOs) (Figure 1). Some of these structures, such as nucleoli, Cajal bodies, and nuclear speckles, were first described more than a century ago [5-7] and, although dynamic structures, they are stable 
enough as to allow their isolation by subcellular fractionation techniques [8]. Others, such as stress granules (SGs) and processing bodies (PBs), have been described more recently and are highly dynamic structures, rapidly condensing or dissolving in response to a wide range of stimuli. Therefore, they are ideally suited to be involved in rapid cellular adaptation to sudden stresses [9], as well as to metabolic changes associated with normal growth [10].

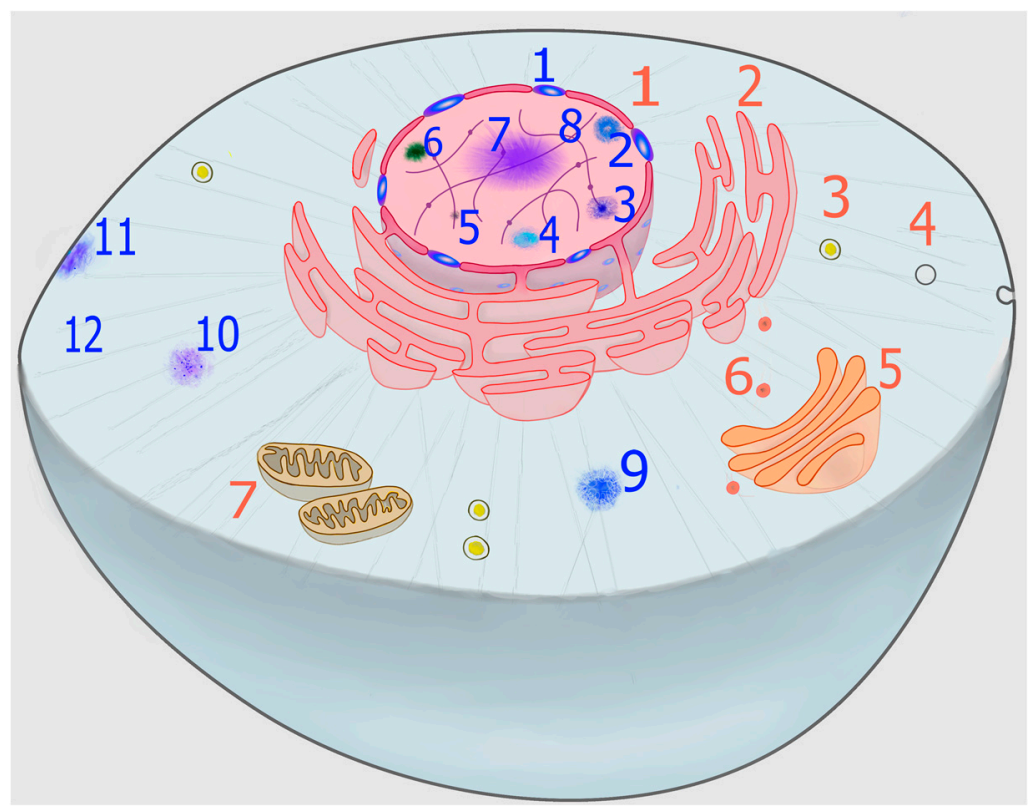

Figure 1. Cellular compartmentalization in eukaryotic cells. The main membranous organelles such as the nucleus (1), endoplasmic reticulum (2), lysosomes (3), endosomes (4), Golgi apparatus (5), vesicles (6), and mitochondria (7) are schematized using warm colors. On the other hand, nuclear MLOs such as nuclear pore (1), nuclear germs (2), PML bodies (3), paraspeckles (4), transcription puffs (5), Cajal bodies (6), nucleolus (7), heterochromatin (8), as well as extranuclear MLOs such as P bodies (9), SGs (10), membrane clusters (11), and cytoskeleton (12) are depicted in cold colors. The list of cellular compartments depicted here is not exhaustive. Some compartments occur only in specific cell types (i.e., synaptic densities and RNA transport granules in neurons; germ granules in germ cells; dicing bodies and photobodies in plant cells; carboxysomes in autotrophic bacteria, or pyrenoids in algae) and they are not shown in the figure.

This battery of MLOs formed by biomolecular condensates is now understood to form via liquid-liquid phase separation (LLPS) of key protein and nucleic acid scaffolds, which recruit and retain, in a specific and regulated way, a wide and varied number of macromolecules (proteins and nucleic acids) that concentrate within the condensate and are referred to as resident clients [11]. Thus, LLPS endows the cell with an organizing principle [12], which allows compartmentalization on an optimal spatiotemporal scale for rapid adaptive responses to the cellular needs of the moment $[9,13,14]$. In contrast to classic membrane-based organelles, biomolecular condensates contribute to the compartmentalization of cellular processes in both eukaryotic and prokaryotic cells [4,15-18]. Although most research in LLPS has been focused on yeast and animal systems, in recent years there has been an increasing interest in the fields of plant science $[19,20]$ and virology [21-24]. Plants are sessile organisms that are subjected to seasonal variance in environmental stressors, facing unique challenges during their life cycles. Therefore, in addition to MLOs that are shared between plants and other organisms, a number of biomolecular condensates that appear to be plant-specific have been described $[19,20]$. On the other hand, proteins of viral origin are also known to undergo LLPS. In a recent review about the relevance of LLPS in viral life cycle, Brocca and coworkers survey available data on LLPS of viral proteins, 
distinguishing LLPS related to viral replication and trafficking of viral components from virus-mediated LLPS processes interfering with host cell functions [23].

Since biomolecular condensates formed by demixing via LLPS seem to be universal, present in the three main domains of life, as well as in viruses, they likely represent the first compartmentalization strategy emergent in life history, driving the subsequent evolution of cellular complexity. In this regard, findings from research fueled by the recent interest in LLPS support the idea, put forward by Alexander Oparin more than nine decades ago, that life originated as coacervate drops of biomolecules accumulated in the primitive oceans [25].

Despite the stunning variety of MLOs described in the literature (Figure 1), it is important to identify unifying principles determining their formation, structure, and function. To this respect, the ability of the so-called scaffold macromolecules to form transient productive interactions (quinary structure) is of paramount importance [26]. This review aims to highlight some of these molecular underpinnings, with particular emphasis on the role that methionine residues from scaffold proteins can play in some cases.

\section{Phase Transition: A Spontaneous Process Harnessed by Living Matter}

Liquid-liquid phase transition is the process through which a solution demixes into two distinct solutions phases, a dense phase and a dilute phase that coexist stably with each other. The dense phase that is enriched in macromolecular solutes (proteins and/or nucleic acids) often resembles liquid droplets. This process is also often referred to as liquid demixing, coacervation or simply condensation (see [11] for a precise definition of the most used terminology in the LLPS field). Phase separation occurs when the macromolecule-macromolecule and solvent-solvent interactions are energetically favored over the macromolecule-solvent interactions (herein, the concept of solvent should be extended to include solutes other than the macromolecules). In this context, LLPS is determined by the balance between two opposite contributions to the free energy of the process: the loss of configurational entropy and the favorable enthalpic term that arises when intrachain interactions are exchanged for interchain interactions, which happens after the concentration of scaffold macromolecules has reached a threshold value [27,28]. On the other hand, the effect of macromolecules on the solvent properties and the resulting interfacial tensions are important factors that, to some extent, have been overlooked and can provide valuable insights into the LLPS behavior of biological systems [29,30].

Due to an avalanche of recent high-impact publications, a long renowned phenomenon known as macromolecular coacervation has moved into the focus of interest. Thus, LLPS, as a cellular mechanism to organize the cellular space and timing, has gained widespread attention across many fields in recent years. However, the observation that proteins tend to coacervate is not novel at all [25]. Since the seventies, it has been known that many enzymatic proteins can reversibly form high-order aggregates in response to changes in the concentration of their effectors [31,32]. Thus, citrate, an allosteric activator of acetyl-CoA carboxylase, induces the polymerization of an inactive protomeric form of the enzyme into an active filamentous form [32,33]. Similarly, mammalian glutaminase, a mainly mitochondrial enzyme [34,35] that can be targeted to the nucleus [36], is known to undergo high order oligomerization with concomitant changes in kinetic properties. Again, these changes are controlled by effectors (both activators and inhibitors) of this enzyme [31,37,38]. Although self-association does not necessarily imply a phase separation process, it has been demonstrated that oligomeric peptides undergo LLPS in vitro, with this process being stimulated by low temperatures, crowding agents, high protein concentrations, and $\mathrm{pH}$ close to the isoelectric point of the peptide [39]. In any event, the observations regarding acetyl-CoA carboxylase and glutaminase highlight two interesting facts: (i) proteins can readily alternate between different aggregation states and (ii) this dynamic alternation can be exploited to fulfil a regulatory role.

On the other hand, since the seventies we have known that glycolytic enzymes interchange between soluble and particulate states depending on different metabolic 
conditions [40-43], suggesting transient interactions that could result in an operative organization of glycolysis at the subcellular level [44]. Since then, the evidence that metabolic enzymes can coacervate has been increasing [45,46], leading to the concept of metabolon [47], defined as a transient structural-functional complex formed by sequential enzymes of a metabolic pathway held together by non-covalent interactions. Yet, the biological relevance of the hypothesized metabolon has remained controversial, mainly because of the lack of studies examining the dynamic distribution of these enzymes in vivo. However, very recently Colón-Ramos and coworkers, using a hybrid microfluidic-hydrogel device and Caenorhabditis elegans as model organism, have proven that phosphofructokinase, that is diffusely localized in the cytosol, can dynamically re-localize into biomolecular condensates in response to transient energy stress [48]. They further determined that these condensates formed in vivo exhibited liquid-like properties, including drop-like shapes due to surface tension, fluidity due to deformations, and fast internal rearrangements, overall suggesting LLPS as the mechanism underlying the formation of these structures, which were previously ruled out to be SGs by the authors of this report [48]. Of interest, a systematic study examining hundreds of yeast metabolic enzymes involved in intermediary metabolism identified the widespread reorganization of these proteins into reversible assemblies upon nutrient starvation [49], suggesting that dynamic compartmentalization into condensates via LLPS could represent an extended regulatory strategy.

The experience of crystallographers, who often observe the phase separation of proteins as a side product of the crystallization process [50,51], also lends support to the view that many, if not all, proteins have an intrinsic ability to undergo phase separation that is manifested in conducive conditions [52]. The ability to be engaged in LLPS may be a universal property of proteins under specific conditions, but for many proteins, such conditions may never be encountered in a cell. That is to say, LLPS may be accessible to a subset of proteins under the conditions that exist within living cells [53]. Thus, identifying the common features of proteins that experience LLPS in a biologically meaningful manner is of paramount importance. In recent years, impressive progress has been made towards understanding the molecular signatures present in molecules that can phase separate under physiological conditions. A brief discussion of this progress is presented next.

\section{Molecular Determinants and Modulators of LLPS}

We have defined phase separation as the process through which a solution transitions from a homogenous state to a demixed two-phase system with lower Gibbs free energy. Characterization of these systems via the empirical construction of phase diagrams, is an approach that has allowed to obtain important insights regarding the molecular determinants that promote the phase separation of scaffold proteins, as well as the conditions $(\mathrm{pH}$, temperature, ionic strength, or macromolecular concentration) that are compatible with LLPS.

\subsection{Concentration of Macromolecules}

Phase transitions are extremely sensitive to macromolecular (protein and nucleic acids) concentration. Within a range of temperature, $\mathrm{pH}$, and salt concentration values, increasing macromolecular concentration leads to demixing (Figure 2). The basis for this observation is that, at high macromolecular concentration, the decreasing free energy due to intermolecular interactions overcompensates for the decreasing configurational entropy. However, this stabilizing contribution is insufficient to compensate for the decreasing configurational entropy unless the macromolecular concentration reaches a threshold value [28]. Furthermore, in some circumstances, it is also important that the scaffold components do not exceed a second, and higher, threshold concentration value [54]. In any case, we are interested in understanding how cells can exploit this concentration-sensitivity to regulate LLPS in a biologically meaningful manner. To illustrate this point, we shall present two examples from very different contexts. 


\section{(A)}

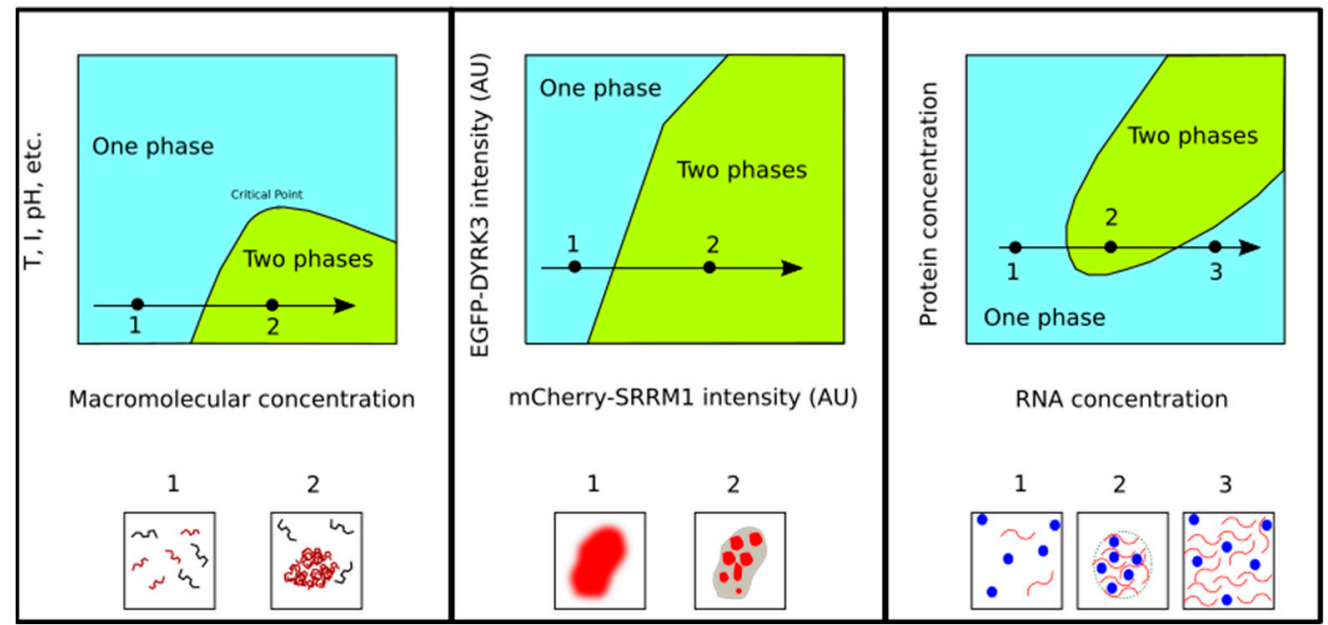

Figure 2. Schematic phase diagrams; (A) The black curve separating the plane into two regions (onephase in cyan and two-phase in green) informs about the conditions (macromolecular concentration; temperature, $\mathrm{T}$; ionic strength, $\mathrm{I} ; \mathrm{pH}$; etc.) at which the two regimes coexist in equilibrium. At a given value of the environmental variable, an increase in the concentration (black arrow) of the scaffold macromolecule leads from the one-phase to the two-phase state (squares 1 and 2, respectively, where the scaffold macromolecules have been represented in red). (B) Schematic representation of the results reported in [55]. In a population of cells expressing the fluorescent tagged proteins EGFPDYRK3 (a kinase with dissolvase activity) and mCherry-SSRM1 (a nuclear substrate of the DYRK3 kinase), nuclear intensities of both signals can be recorded and plotted in a Cartesian plane using arbitrary units (AU). The black line splitting the plane in two regions is given by the kinase/substrate ratio above which the nuclear condensates containing SSRM1 melt. Thus, at a fixed value of kinase concentration, moving from lower to higher concentrations of the kinase substrate (black arrow) leads to the assembly of condensates (square 1 and 2, respectively). (C) Phase diagram of RNA-protein mixtures. The black arrow represents, at a given protein concentration, the direction in increasing RNA concentrations. An initial increase in RNA concentration drives phase transition from one phase (square 1) at low RNA levels to two phases (square 2) at intermediate levels of RNA. Further increasing the RNA concentration drives the second phase transition, now from two phases (square 2) to one phase (square 3) after dissolution of the condensates. This process, known as RNA-mediated reentrant phase transition, is thought to be driven by electrostatic forces.

Upon entering mitosis, many MLOs melt and then later, during telophase or after the completion of mitosis, reappear again [56,57]. Experiments carried out using human cells suggest that the timing of these LLPS processes is regulated by the dual specificity tyrosinephosphorylation-regulated kinase 3 (DYRK3), a protein kinase that acts as a dissolvase of MLOs during the G2 to M transition, after the nuclear envelope breakdown [55]. If upon entry into mitosis MLOs disassembly occurs via DYRK3, one could naively hypothesize that its dissolvase activity should suddenly increase at the beginning of mitosis and then reduce at the end of mitosis. However, Rai and collaborators did not observe such a sudden increase in DYRK3 levels as cell entered mitosis [55]. Thus, to explain how DYRK3 drives the disassembly of MLOs during mitosis, these authors noted that upon breakdown of the nuclear envelope, the concentration of DYRK3 relative to its substrates suddenly increase. That is possible because key substrates of DYRK3 are exclusively located in either the nucleus (serine/arginine repetitive matrix protein 1, SRRM1) or the cytoplasm (pericentriolar material 1 protein, PCM1), while DYRK3 itself is found in both compartments. Thus, when the cell enters mitosis and the nuclear barrier is removed, the concentrations of the DYRK3 substrates, but not that of the kinase, are diluted. In line with this explanation, these authors observed a sharp phase boundary in their phase diagrams, at a specific 
DYRK3-to-SRRM1 ratio, below which SRRM1 would be condensed and above which it would be dissolved (Figure 2B).

The other example, illustrating the effect of macromolecular concentrations on condensate formation, comes from the transcriptional regulation field. Thus, in a recent paper, Henninger and coworkers describe a non-equilibrium feedback control mechanism for the regulation of transcription. According to the proposed model, at a low concentration of nascent RNAs, electrostatic interactions promote the formation of transcriptional condensates, whereas the burst of RNAs produced during elongations trigger the condensate dissolution (Figure 2C), providing a feedback mechanism [58]. This phenomenon where RNA at low concentration drives the formation of droplets, while high RNA concentrations lead to the dissolution of these droplets, is referred to as reentrant phase transition (RPT) [54]. An electrostatic mechanism seems to be behind RPT. Indeed, many RNA-binding proteins that undergo LLPS present intrinsically disordered regions (IDRs) enriched in basic (arginine and lysine) residues [59]. Therefore, when these proteins are in contact with low RNA concentrations, short-range electrostatic attractions lead to charge neutrality, favoring the formation of biomolecular condensates. However, when RNA is found at high concentrations, long-range Coulombic repulsion derived from a charge inversion will drive the dissolution of these condensates [60,61].

\subsection{Multivalency}

LLPS of scaffold proteins and the subsequent partitioning of clients to form MLOs rests on the establishment of a network of intermolecular interactions. Therefore, scaffold proteins must be equipped with a domain architecture that facilitates such interactions. Two archetypes of protein architectures optimal to promote interaction networks have been distinguished, both having multivalency in common. That is, the protein presents multiple motifs able to interact with their partners [53].

The first archetype consists of multiple structured domains, such as $\mathrm{SH} 2$ and $\mathrm{SH} 3$, that interact with short linear motifs in their partner proteins, such as phosphotyrosine or proline-rich motifs, respectively. The role that these folded domains can play in LLPS has been smartly documented by $\mathrm{Li}$ and coworkers, who generated two classes of engineered proteins, one composed of repeats of a single $\mathrm{SH} 3$ domain $\left(\mathrm{SH}_{3} \mathrm{~m}\right.$, were $\left.\mathrm{m}=1-5\right)$ and the other composed of repeats of proline-rich motifs $\left(\mathrm{PRM}_{\mathrm{n}}\right.$, where $\left.n=1-5\right)$ [62]. Using different combinations of these engineered proteins, they observed LLPS, whose phase boundary was strongly dependent on the valency of the mixed proteins. That is, the concentrations needed for phase transition were directly related to the valency of the interacting species $\left(\mathrm{SH}_{\mathrm{m}}-\mathrm{PRM}_{\mathrm{n}}\right)$. Of interest, this behavior observed in vitro was mirrored in living cells. Thus, HeLa cells co-expressing mCherry-SH3${ }_{5}$ and eGFP-PRM ${ }_{5}$ formed cytoplasmic foci containing both fluorophores. However, these condensates were not observed in cells expressing either protein alone or in cells co-expressing fusion proteins with lower valences [62].

The second archetype is characterized by the presence of RNA recognition motifs (RRMs) as well as intrinsically disordered regions (IDRs) of low complexity (LC) [63]. These domains show biased amino acid compositions. The amino acid composition of these domains and their disposition in the modular architecture of the scaffold proteins determine the networks of weak but cooperative interactions that can be formed, which in turn govern the LLPS process [64]. Of note, the sort of interactions critical for LLPS are of the same nature as the interactions that drive protein folding and stabilize the tertiary structure of proteins $[65,66]$. Thus, LC domains rich in aromatic residues (tyrosine and phenylalanine) are favored to form $\pi-\pi$ stacking interactions [64,67]. Although $\pi-\pi$ interactions are commonly associated with aromatic rings, $\pi$ orbitals of bonded $\mathrm{sp}^{2}$-hybridized atoms, as those found in peptide backbone amide groups, may also be involved in stabilizing interactions. In this regard, residues such as glycine, serine, threonine, and proline (often found to be overrepresented in LC regions) have small side chains. This reduced size 
implies relatively exposed backbone peptide bonds enabling planar $\pi$ interactions that can contribute to phase separation [68].

On the other hand, RRMs are enriched in basic amino acids that facilitate the binding of negatively charged RNA molecules, but these basic residues (mainly arginine [69]) can also interact with aromatic amino acids to form cation- $\pi$ interactions, which have been shown to be critical in modulating FUS (fused in sarcoma) phase separation [64,70]. In addition to mediate protein-nucleic acid binding, charge-charge interactions are also relevant in protein-protein interactions, playing a prominent role in the phase separation of certain scaffold proteins. For instance, DEAD-box helicase $4(\mathrm{Dd} \times 4)$, a protein essential for the assembly and maintenance of the related nuage in mammals, contains alternating clusters of net negative and net positive charge. To address the importance of this charge distribution in phase separation, Nott et al. constructed a Ddx4 mutant, with the same overall net charge but in which the clusters were scrambled. The mutated proteins were unable to support LLPS [71].

Hydrogen bonds also can be important in driving phase separation. All amino acids may participate in hydrogen bonding, either as hydrogen bond donors or acceptors. However, the most prone are polar ones. Indeed, NMR and simulation techniques have shown that glutamine residues abundant in the LC region of FUS are important determinants of phase separation, being hydrogen bonding highly prevalent [72].

In general, what interactions contribute proportionally more to LLPS, and how these interactions may be tuned by environmental conditions, will depend on the specific amino acid composition of a given scaffold protein. In other words, different proteins may resort to different combinations of interactions, thus enabling a selective regulation. To illustrate this point, later, we will focus our attention on a group of scaffold proteins whose LC regions contain an unusually high frequency of methionine $[14,73,74]$ Methionine is an amino acid known to participate in a number of non-covalent bonds, some of them highly specific for this amino acid $[75,76]$, that overall contribute to protein stability. Therefore, methioninedependent interactions may be key elements in the LLPS process of this group of proteins. Nevertheless, since the role of methionine in LLPS is a subject of particular interest in the current review, we will address its discussion in more detail in a subsequent section.

\subsection{Intrinsic Disorder}

In the preceding section we have introduced the concept of intrinsically disordered regions in the context of multivalency. Now, in the current section we would like to emphasize the importance of intrinsic disorder in phase separation. To this end, we will briefly summarize the role that IDRs play not only as drivers of the LLPS process, but also as key regulators of the composition, stability, and functionality of the diverse MLOs that can be formed within cells.

IDRs constitute a significant fraction of any known proteome, with the percentage of residues from the whole proteome involved in disorder ranging from $12 \%$ to $36 \%$ [77]. What characterizes a protein, or a region of a protein, as intrinsically disordered is that it fails to form a unique, predominantly stable 3D-structure, yet IDRs fulfil many biologically important functions [78]. Their inability to adopt a fixed structure is encoded by their amino acid sequences. Although IDRs can appear in different flavors, depending on the amino acid composition bias exhibited [79], in general they are deficient in canonical hydrophobic residues, which are core residues for folded domains, but are enriched in structure-breaking amino acids that make IDRs flexible enough to dynamically adopt different conformations that populate a flat energy landscape. As we will argue later on, this high conformational heterogeneity is critical to the role these proteins play in MLO biology.

An overwhelming number of different MLOs have been described in the literature, and the list keeps growing as new cellular biomolecular condensates continue to be discovered on a regular basis [77]. These MLOs come in varied sizes and shapes, they have different composition, and they show specific biophysical and biochemical properties, likely reflecting the requirements of the different cellular processes in which they partic- 
ipate, as well as the specific regulatory needs of these processes. However, a common denominator is that almost invariantly all these MLOs contain proteins with IDRs [77]. This observation raises a question: What are the features of IDRs that make them so relevant in the biology of MLOs?

An obvious explanation, that we have already discussed in the previous section, is that IDRs contribute to the multivalency phenomenon via their tailored LC regions. Furthermore, the conformational flexibility exhibited by IDRs allows the interacting residues (stickers) to be spatially disposed to yield productive bindings while avoiding unspecific contacts, which is particularly important in the context of an overcrowded milieu as is the case of biomolecular condensates [77]. Another important feature of IDRs is that they usually cluster amino acids susceptible to post-translational modifications (PTMs). Indeed, the lack of a compact 3D-structure facilitates the accessibility of the target sites to various PTMs. As will be discussed in a subsequent section, PTM is relevant to the regulation of LLPS.

A further interesting consideration, regarding the suitability of IDRs as MLOs constituents, is their contribution to the stability and resilience of the supramolecular structures of which they are part. Despite the lack of membranes and the fact that their constituents are freely exchanged with the environment, MLOs are stable entities. As paradoxical as it may sound, Uversky postulates that the lack of structure in IDRs is what determines the stability and resilience of cellular condensates [80]. This author argues that "there is a remarkable difference in the resilience of rigid complexes formed by rigid blocks and stabilized via the specific and high affinity block-block interactions and fluid complexes made of flexible constituents". In other words, while structured supramolecular complexes are much less resistant to the loss of any of their components, biomolecular condensates can either gain or lose IDRs components without drastic changes in the overall stability of the condensate.

\subsection{Transient Secondary Structural Elements}

Apart from amino acid side chain interactions, LLPS can be influenced by secondary structural elements [81,82]. Within the LC region of scaffold proteins, stretches of amino acids can assemble into intermolecular cross- $\beta$ sheets resembling those typically found in amyloid fibrils [83]. However, structural studies of fibrils formed by short segments of the LC regions from proteins that undergo LLPS, have uncovered important differences with classic amyloid fibrils. Thus, while amyloid fibrils tend to have cross- $\beta$ sheets with interdigitated amino acids that form steric zippers, those fibrils formed by short segments of the LC region of proteins, being phase separated, have kinked cross- $\beta$ sheets, and are referred to as low-complexity aromatic rich kinked segments (LARKS) [84]. Unlike steric zippers of amyloid fibrils, the kinked sheets are thermodynamically less stable, providing a reversible force for the assembly/disassembly of biomolecular condensates [85].

\section{Posttranslational Modifications Others than Methionine Sulfoxidation}

Life uses a common set of 20 coded amino acids to build proteins. The physicochemical diversity covered by this set of proteinogenic amino acids can be extended further through PTMs of the side chain of most of these amino acids. More than 400 different PTMs have been described [86]. Often, PTM involves the addition of chemical functional groups to the side chain of target residues. These modifications range from the addition of a single atom (e.g., sulfoxidation of methionine) to the addition of a whole polypeptide chain (e.g., ubiquitination of lysine). In other cases, PTMs involve the modification of the chemical properties of the target amino acid by replacing one chemical functional group with another. Thus, the deamidation of glutamine and asparagine or the deimination of arginine (also called citrullination) are examples belonging to this last category.

Each of these PTMs has, independently, the potential to regulate the activity of the modified protein, its subcellular location, its stability (folding), its affinity for other cellular components, etc. In addition, in recent years, the possibility of interrelationships between 
different PTMs (cross-talk) has begun to generate great interest [87]. These interrelations allow an enormous expansion of the degree of regulation and the number of functional states that a single protein can reach. Thus, combining multiple PTMs, a single protein can yield a large number of proteoforms [88], which has led to the concept of PTM code [89]. In summary, because of the potential to elicit an additive, cooperative, or competitive integrated response [90], the PTM code can provide many layers of complex biological regulations that are not yet well understood.

Because of their accessibility to modifying enzymes, IDRs found in scaffold proteins are the predominant sites of PTMs [91]. Since LLPS is driven by a network of residue-toresidue interactions, modifications of these residues from IDR can alter, either increasing or weakening, the network of interactions. As we have seen above, arginine is a key amino acid involved in LLPS-driving interactions. Indeed, this basic residue can take part in (i) cation- $\pi$ bonds, (ii) salt bridges, (iii) or participate in the binding of nucleic acids. In addition, arginine specifically binds ATP, which biphasically modulates LLPS of the scaffold protein TDP-43 [92]. Not surprisingly, arginine modification by members of the protein arginine methyltransferase (PRMT) family plays a suppressive role in phase separation $[70,71,93,94]$. PRMTs catalyze the transfer of one or two methyl groups from S-adenosylmethionine to the nitrogen atoms of the guanidinium group of arginine [95]. Interestingly, the cellular concentration of S-adenosylmethionine has been proposed as a regulator of SG composition and assembly [96]. Although arginine methylation is thought to reduce LLPS, this modification may fulfil more complex regulatory roles, affecting the dynamics and functional properties of biomolecular condensates in numerous and different ways [97].

Beside arginine methylation, citrullination, the conversion of arginine into citrulline, is another PTM that targets arginine residues and can impact the LLPS process [98]. This conversion is catalyzed by the peptidyl arginine deiminase (PAD) enzyme family, which replaces the imine group of arginine by a carbonyl group [99]. In this way, the positively charge guanidinium group, $-\mathrm{NH}-\mathrm{C}\left(\mathrm{NH}_{2}\right)_{2}{ }^{+}$, is transformed into a neutral urea group $\left(-\mathrm{NH}-\mathrm{CO}-\mathrm{NH}_{2}\right)$. It seems that arginine citrullination reduces the multivalent interactions between tyrosine and arginine residues and hence has a inhibitory effect on LLPS [97].

Unlike arginine methylation, considered a rather stable modification [95,100], phosphorylation of serine, threonine and tyrosine residues is a highly dynamic PTM playing a relevant role in the control of biomolecular condensates (reviewed in [90,97]). Replacing the neutral hydroxyl group $(-\mathrm{OH})$ of the phosphoacceptor residue with a bulky phosphoryl group $\left(-\mathrm{PO}_{4}{ }^{2}\right)$ entails a drastic change of the steric, chemical, and electrostatic properties of the affected side chain, introducing new interaction capabilities. Thus, the introduced negative charges can form strong salt bridges, mainly with arginine residues due to the rigid planar structure of the guanidinium group, and its ability to form multiple hydrogen bonds [101]. Phosphorylation can also affect the stability of secondary structure elements, either increasing or decreasing them. Thus, phosphoserine located at the N-terminal positions of the helix has a stabilizing effect, while it has a destabilizing repercussion in the helix interior [102]. Phosphorylation may also interfere with the hydrogen bonding affecting the formation of cross- $\beta$ structures. That has been suggested to be the cause of the reduced phase separation of the scaffold protein FUS after phosphorylation by DNA-PK of serine and threonine residues from its LC region [97].

In contrast to FUS, where phosphorylation has a suppressive effect on phase separation, a high degree of tyrosine phosphorylation on the IDR cytoplasmic tail of nephrin promotes the phase transition in the assembly of multivalent signaling aggregates [62]. Nephrin has six potential phosphotyrosine sites, each of which can interact with $\mathrm{SH} 2$ domains from NCK, an adaptor protein. In addition to SH2 domains, NCK also has $\mathrm{SH} 3$ domains able to interact with six proline-rich motifs of N-WASP, a protein that regulates actin polymerization by stimulating the actin-nucleating activity of the Arp2/3 complex [103]. Tau, a neuron-specific protein, also illustrates how phosphorylation can 
favor phase separation. Thus, serine phosphorylation in the microtubule binding domain of Tau, which is lysine-rich, drives electrostatic coacervation promoting LLPS [104].

Other PTM that appears to be involved in the regulation of LLPS is acetylation of lysine residues. Thus, this modification has been shown to decrease phase separation of the proteins Tau [105,106] and RNA helicase DDX3X [107], a component of SGs. Furthermore, the deacetylase enzyme HDAC6 seems to be required for SG formation [108]. Likewise, O-GlcNAcylation of serine and threonine residues has been described to cross-talk with phosphorylation in Tau [109] and hnRNPA1 [110]. In summary, although the role of cross-talk between different PTMs in the control of LLPS is currently ill defined, it can be anticipated that future work to disentangle the PTM code will provide interesting insights regarding the dynamics and regulation of MLOs formation.

\section{Role of Methionine Residues in Modulating LLPS}

The oxidation of protein-bound methionine to form methionine sulfoxide (MetO) has traditionally been regarded as an undesirable and harmful consequence of oxidative stress, linked to age-related malfunctions [111-114]. More recent works have allowed to broaden and enrich this view. Thus, investigations from a number of laboratories support the notion that reversible protein methionine sulfoxidation can act as an antioxidant buffer system [115-118]. In addition, methionine oxidation activates transcription factors in response to stimuli $[119,120]$, regulates the cytoskeleton dynamics [121-123], and the activity of key signaling protein kinases $[124,125]$, just to mention a few examples. The interconversion of Met and MetO also influences protein stability and protein-protein interactions (PPI) [76,126]. A more comprehensive information regarding the impact on biology of methionine oxidation can be consulted in the database MetOSite, a resource devoted to this end [127]. Although the oxidation of methionine residues has been reported to have multiple and varied implications for protein function, in the remaining sections of this article we will focus on very recent findings that identify reversible methionine oxidation as a redox sensor involved in the dynamic assembly/disassembly of biomolecular condensates. These studies represent a breakthrough, as they provide insight into how MLOs can act as coupling agents that sense the metabolic state of the cell and develop appropriate adaptive responses $[14,73,74,128]$.

\subsection{Short Overview on Methionine Properties Relevant for LLPS}

Methionine, an aliphatic sulfur-containing molecule, is endowed with physicochemical properties that make it a unique proteinogenic amino acid. Next, we point out some of these properties that could be relevant to understand the role of methionine residues in LLPS and its regulation. A more detailed description of these properties and the discussion of their relevance in a wider biological context can be found at [129].

Although methionine is considered a hydrophobic amino acid, unlike other hydrophobic residues such as leucine, isoleucine or valine, methionine has an unbranched side chain, which provides ample flexibility. In this way, when patches of methionine residues are arranged in the primary structure of a protein, the extra-flexibility of methionine provides a malleable nonpolar surface that can adapt itself to peptide binding partners, favoring the proximity between atoms from different polypeptide chains and the subsequent van der Waal's interactions [130]. Furthermore, the larger polarizability of sulfur with respect to carbon also leads to greater London dispersion forces.

A third property that also contributes to the plasticity of methionine residues during PPIs is related to the $\mathcal{X}_{3}$ torsion angle, which controls the position of the $\varepsilon$-methyl group. A statistical survey of a wide sample of proteins revealed that $\mathcal{X}_{3}$ remained virtually flat over the entire range of possible values [131]. This observation implies that the side chain of methionine shows very little energetic preference between different conformations, which in turn confers to methionyl residues a wide freedom to mold themselves to accommodate binding partners. Overall, these properties make methionine stand out from the rest of the hydrophobic amino acids. Next, we present an intermolecular interaction of a very 
different nature to the weak van der Waals forces described above. This interaction, which is referred to as an S-aromatic bond, places the methionine sulfur atom at the center of the picture [132-134].

Indeed, a remarkable property derived from the presence of a sulfur atom in the side chain of methionine is the potential to interact with nearby aromatic residues, such as tyrosine, phenylalanine, and tryptophan, to form the so-called S-aromatic motif [75]. These motifs can computationally be identified on the basis of geometric considerations, including the interatomic distance between the sulfur atom of methionine and the centroid of the aromatic ring [135]. Thus, when this distance is below the threshold of $7 \AA$, the interaction can have an associated energy comparable to that of a salt bridge. However, the strength of these non-covalent bonds can vary dramatically depending on the environment around the sulfur $[126,136,137]$, which may be exploited from a regulatory point of view, as we will discuss later.

Finally, the sulfur atom of methionine can be readily oxidized to form methionine sulfoxide (MetO). This oxidation reaction can be catalyzed by enzymes [122,123,125,138]. However, the number of proteins proved to be oxidized in an enzyme-catalyzed reaction is very small. Although we can anticipate that this list will be extended in the future, only three proteins are included in it, namely calmodulin [138,139], F-actin [122,123], and $\mathrm{Ca}^{2+} /$ calmodulin-dependent protein kinase II (CaMKII) [125]. Nevertheless, hundreds of proteins are known to be sulfoxidized within living cells in response to oxidative stimuli [140]. Furthermore, many of these oxidation sites seem to be selectively targeted rather than randomly modified [141]. In any event, MetO can be reduced back to methionine in a reaction catalyzed by methionine sulfoxide reductases (Msrs), enzymes present in all eukaryotic cells and in most prokaryotic cells [142]. Therefore, the oxidation/reduction of methionyl residues represents a reversible post-translational covalent modification, particularly suitable for sensing the cellular redox state and mediating redox signaling [141,143].

\subsection{Effects of Methionine Oxidation on Transient Protein-Protein Interactions}

The simple covalent addition of an oxygen atom to the sulfur atom of methionine residue can cause drastic changes in the properties we have outlined above. These changes, in turn, can impact the physicochemical properties of the whole protein. Since PPIs are a relevant aspect of LLPS, we next focus on the influence of methionine sulfoxidation on these interactions.

Perhaps the most obvious change caused by the oxidation of methionine is the conversion of an apolar side chain into a highly polar one. Thus, the side chain hydrophobicity index decreases from 0.738 (Met) to 0.238 (MetO) after the incorporation of the oxygen atom [144]. This decrease in hydrophobicity is behind the rationale of using glutamine (hydrophobicity index of 0.251 ) in mutagenesis experiments to mimic the sulfoxidized state of a protein $[119,139]$. Here, a caveat is in order. Although glutamine and MetO exhibit a remarkable structural similarity and almost identical polarity, the amido group-containing glutamine still packs well into $\alpha$-helices, in contrast to MetO [145]. In any case, whether it is due to a simultaneous increase in polarity and bulkiness while losing flexibility or due to a loss of secondary structure, methionine sulfoxidation seems to impair protein-protein interactions [73,74] more often than favoring them [126,146]. Thus, although the oxidation of methionine residues has been reported to favor the formation of cross- $\beta$ amyloid structures, this behaviour is most likely a colateral effect subsequent to a partial unfolding of the protein [146].

We have previously underlined the importance of a flexible side chain for promoting close contact between two hydrophobic surfaces, each one belonging to one of the interacting proteins. However, if we aim to understand the role of methionine sulfoxidation in the control of PPI, we must first address two issues. On one hand, since the reactivity of protein-bound methionine against oxidants is strongly influenced by the accessibility of the sulfur atom [147], how is it possible to oxidize methionine residues that are forming part of these contact surfaces that are excluded from the medium? On the other hand, 
since we are considering transient PPIs, does it mean that the protein, in the absence of its partner, exposes large hydrophobic patches to the surrounding medium? Although, on the basis of theoretical considerations, different scenarios could be proposed to reconcile these problematic issues with a role for methionine modification in the regulation of PPI, we would rather limit ourselves to those explanations that seem to have an experimental support [74]. To this end, we next review in detail the work carried out with a few proteins that we could take as paradigms in the redox control of LLPS.

\section{3. $T D P-43$}

TAR DNA-binding protein 43 (TDP-43) is a protein involved in RNA biogenesis and processing [148]. It has been implicated in the formation of neural granules, and contributes to localize dendritic translation at synapses [149]. The domain architecture of this protein (Figure $3 \mathrm{~A}$ ) contains a structured N-terminal domain that facilitates homotypic oligomerization [150,151], two RNA recognition motifs (RRM), and a low complexity (LC) region that is identified as a prion-like domain (PrLD). Both elements, RRM and PrLD, are features present in many proteins able to undergo LLPS, which are prone to misfolding and aggregation, processes linked to neurodegenerative diseases [63]. A number of mutations in the gene encoding TDP-43 have been related to neurodegenerative diseases $[63,152]$. Not surprisingly, in recent years, TDP- 43 has emerged as one of the most intensively studied proteins in the field of neurodegenerative diseases. Despite all this research effort, we still have only an incomplete and fragmented view of the biochemistry of this protein. Nevertheless, we can point some interesting facts: (i) the vast majority of the diseasefavoring mutations are found in the C-terminal PrLD of the protein $[63,153]$, (ii) the PrLD is essential for recruitment of TDP-43 into SGs [154], (iii) studies done on recombinant purified TDP-43 suggest that a region within the PrLD might form the core of TDP-43 aggregation [155]. 
(A)

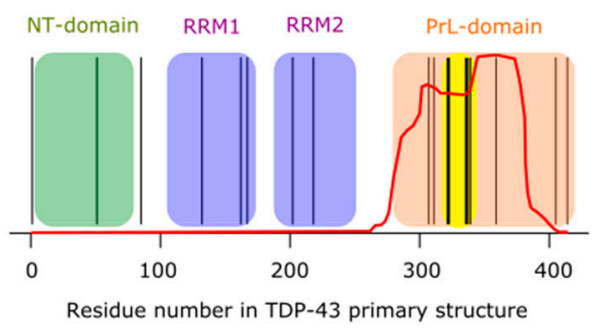

(B)

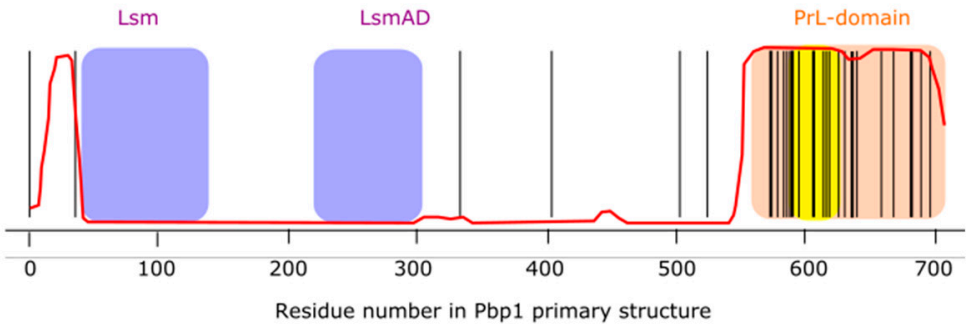

(C)

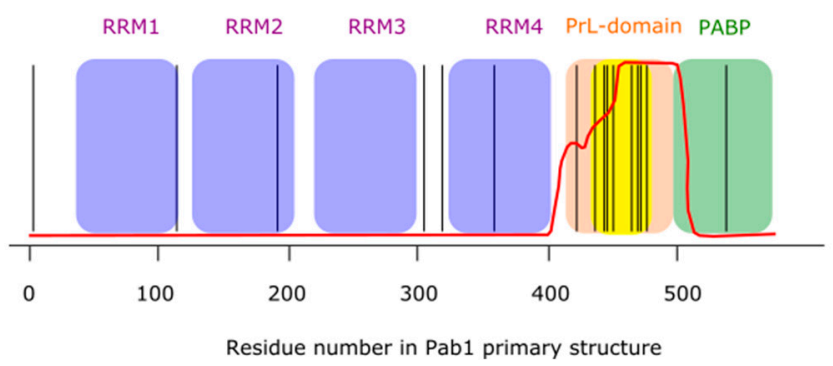

Figure 3. Modular architecture of three scaffold proteins containing methionine-rich LC domains. Methionine positions in the primary structure are indicated by vertical black lines. (A) TDP-43 presents a folded $\mathrm{N}$-terminal domain (green box) with six $\beta$-strands [151], which has been shown to play an important role in the aggregation of TDP-43 monomer. This protein also has two RRMs (blue boxes) and a PrL domain (salmon box) that host a redox sensor formed by methionine residues (yellow box). (B) Pbp1, the yeast ataxin-2 orthologous, exhibits two RNA binding domain, Lsm and LsmAD, (blue boxes) and one methionine-rich LC regions (salmon box) containing a redox sensor (yellow box) that controls the aggregation ability of the protein. (C) Pab1 has 4 RRMs (blue boxes) one PrL domain (salmon box) enriched in methionine residues (yellow box) and a poly(A)-binding protein (PABP) domain towards the $\mathrm{C}$-terminal of the polypeptide chain (green box). The red curves represent the score provided by the software PLAAC for each protein sequence. PLAAC uses Hidden Markov Models to compute the probability of a region from the analyzed protein being an LC region belonging to the PrLD category [156].

These observations have led to the view that PrLDs tend to behave as autonomous aggregation modules that, eventually, may adopt amyloid-like pathological conformations. However, based on recent findings, Franzmann and Alberti have proposed a rather opposite perspective. According to these authors, PrLDs may have evolved to regulate LLPS and to protect cells against proteotoxic damage [157]. The arguments given to support this picture are as follows. The folded domains of RNA-binding proteins, in order to carry out its functions must interact with its natural ligands, such as RNA, nucleotides, and other binding partners. These functional requirements may have imposed evolutionary 
constraints that make these domains highly prone to aggregation. In this scenario, PrLDs may act as regulatory elements that avoid aberrant behaviors of the whole protein by acting as modifiers of protein phase transitions that adjust the solubility of proteins and protect them from misfolding [157]. Hitherto, the description we have presented of the LC region of TDP-43 could easily be generalized to that of many other RNA-binding proteins containing PrLDs. Now, we will focus on the peculiarities of the TDP-43 PrLD.

The PrLDs of many RNA-binding proteins are characterized by a high abundancy of tyrosine and/or phenylalanine. The cation $-\pi$ interaction established between these aromatic residues from the PrLD and arginine residues from the RRMs, has been proved to be determinant in setting the protein saturation concentration during LLPS [64]. In contrast, the LC domain of human TDP-43 only contains one tyrosine and five phenylalanine residues. However, in addition, it departs from prototypic PrLDs in the presence of 10 evolutionary conserved methionine residues expanding from residue 307 to 414 from the human sequence [74]. Although there exists certain controversy with regard to whether this protein region could be involved or not in the formation of cross- $\beta$ assemblies during LLPS in vivo [85,158], McKnight and coworkers have recently reported convincing arguments in favor of the view that labile cross- $\beta$ structures may be responsible for the formation of droplets in vitro, as well as condensates within living cells. Furthermore, these authors also delineate the key role played by methionine residues both in the formation of the aggregates and in sensing the conditions leading to their disassembly [74].

A first experimental indication that methionine residues from the LC region of TDP-43 may play a key role during condensation came from in vitro experiment with purified protein. Thus, the authors expressed recombinant proteins containing the terminal 152 residues of TDP-43 fused to different tags. When these proteins were incubated under physiological conditions (regarding monovalent salt concentrations and $\mathrm{pH}$ ), the solutions were able to transit into a gel-like state that, when evaluated by X-ray diffraction, yielded prominent cross- $\beta$ diffraction rings at 4.7 and $10 \dot{A}$. Prior to gelation, light microscopic examination of the solutions revealed droplets with diameters ranging from 2 to $10 \mu \mathrm{m}$. Interestingly, when the observed droplets were exposed to varying concentrations of hydrogen peroxide $\left(\mathrm{H}_{2} \mathrm{O}_{2}\right)$, a progressive melting of the droplets was observed until droplets fully disappeared at $0.3 \% \mathrm{H}_{2} \mathrm{O}_{2}$. By contrast, when the LC region of TDP-43 was substituted by that of FUS, another RNA-binding protein that undergoes LLPS but that only contains a single methionine residue in its LC domain, no evidence of melting could be obtained even upon exposure to $1 \% \mathrm{H}_{2} \mathrm{O}_{2}$. In line with the hypothesis that droplet melting was caused by the oxidation of methionine residues, droplet reformation was observed upon the addition of a mixture of MsrA, MsrB, thioredoxin, thioredoxin reductase, and NADPH. Msrs enzymes are known to reduce MetO back to methionine in the presence of thioredoxin, thioredoxin reductase and NADPH [159]. Furthermore, direct evidence of the $\mathrm{H}_{2} \mathrm{O}_{2}$-driven methionine oxidation of the TDP-43 PrLD was provided by mass spectrometry [74].

As we have pointed out in the previous subsection, those methionines forming part of a structured contact surface are expected to exhibit a lower reactivity against oxidants than those that are more accessible to the solvent [147]. Based on this rationale and using an isotopic labeling strategy described elsewhere [160], Lin and coworkers designed a method of $\mathrm{H}_{2} \mathrm{O}_{2}$-mediated footprinting that they applied to characterize cross- $\beta$ polymers formed from the TDP-43 PrLD. Briefly, polymeric forms of the TDP-43 PrLD were exposed to limiting concentrations of ${ }^{16} \mathrm{O}$-labeled $\mathrm{H}_{2} \mathrm{O}_{2}$ to allow the oxidation of only those methionine residues being more exposed/reactive. Afterward, the excess of oxidant was quenched, and the desalted protein was denatured by treatment with $6 \mathrm{M}$ guanidine $\mathrm{HCl}$. Completely unstructured protein was then exposed to ${ }^{18} \mathrm{O}$-labeled $\mathrm{H}_{2} \mathrm{O}_{2}$. In this way, those methionine residues that remained unoxidized because they were protected while forming part of a cross- $\beta$ structure should now be exposed and oxidized. Therefore, methionines involved into the formation of cross- $\beta$ polymers should show a high ${ }^{18} \mathrm{O} /{ }^{16} \mathrm{O}$ ratio when analyzed by mass spectrometry (Figure 4). Using this elegant experimental design, the footprint of 
TDP-43 in liquid-like droplets showed Met322 and Met323 to be substantially protected from the oxidant, which points to these residues as integrant of the cross $-\beta$ core. A parallel result was obtained when the oxidation with ${ }^{16} \mathrm{O}$-labeled $\mathrm{H}_{2} \mathrm{O}_{2}$ took place within living cells and then solubilized and immunoprecipitated TDP- 43 was treated with ${ }^{18} \mathrm{O}-$ labeled $\mathrm{H}_{2} \mathrm{O}_{2}$. Again, Met322 and Met323 showed a much higher ${ }^{18} \mathrm{O} /{ }^{16} \mathrm{O}$ ratio, suggesting that they form part of a structured segment of the protein, most likely a cross- $\beta$ structure [161]. As a note of interest, multiple sequence alignment of 11 vertebrate species ranging from fish to human reveals that the 23 residue long segment ${ }^{319}$ NPAMMAAAQAALQSSWGMMGMLA ${ }^{341}$ (numeration corresponding to the human sequence) remained conserved after the last common ancestor split some 500 million years ago [74]. Interestingly, this segment also coincides with a cross- $\beta$ structure formed by segments of the TDP- 43 protein characterized by cryo-EM [161]. Furthermore, mutations of methionine from this segment to either valine or isoleucine have been related to neurodegenerative diseases [63].

If we accept that oxidants arising inside cells, as consequence of their activities, control the assembly/disassembly of TDP-43 condensates, we must still answer the question we posed earlier about how oxidants can reach and modify these methionine residues that are structurally shielded from the medium. Since the oxidation of buried and structured methionines is known to be promoted by the previous oxidation of neighboring methionines that are more exposed or flexible [162], McKnight and colleagues have put forward the following hypothesis. Methionines 336, 337, and 339, which, according to the footprint, are more reactive than Met322 and Met323, may form part of a redox switch that is evolutionarily conserved. When the concentration of oxidants rises above a threshold, e.g., as consequence of active synapses that are mitochondria-rich, then the most accessible methionine residues may be oxidized to sulfoxide. This modification, that as we have discussed above can be structurally destabilizing, could trigger a cascade of movements leading to minor local loss of structure, but enough to eventually facilitate the access of oxidants to those methionines involved in the maintenance of the condensates.

\subsection{Ataxin-2}

Like TDP-43, ataxin-2 is an RNA-binding protein identified as a genetic determinant or risk factor for various neurological diseases, including spinocerebellar ataxia type II and amyotrophic lateral sclerosis, among others [163]. Ataxin-2 is a modular protein involved in many different cellular processes, including the regulation of RNA stability, RNA translation, regulation of cellular metabolism, and circadian rhythms [163]. Being a modular protein (Figure 3B), its size varies widely between orthologous, ranging from 301 residues in the Paramecium tetraurelia to 1392 amino acids in the chimp orthologous [164]. However, most orthologous proteins contain at least three well conserved domains, e.g., Lsm, LsmAD, and PAM2, and are believed to be involved in (i) mRNA binding and processing, (ii) Clathrin-mediated trans-Golgi trafficking, and (iii) interactions with poly(A)binding protein, respectively [165]. Although a PAM2 motif has not been identified in the orthologous proteins from Saccharomyces cerevisiae and C. elegans, both proteins can interact with poly(A)-binding protein [164], most likely via LC regions found towards the C-terminal end of the protein [166]. In addition to these well characterized motifs, ataxin-2 proteins contain LC PrLDs that may play key roles in the assembly of cytoplasmic MLOs including P-bodies, SGs and neural granules [167]. In this respect, recent work from the laboratories of Benjamin Tu and Steven McKnight have provided strong evidence of the relevance of LC PrLD of Pbp1, the budding yeast orthologous of ataxin-2, in the control of LLPS in response to metabolic demands [74,128]. This work represents a breakthrough because it provided the first evidence of a fascinating new mechanism, based on the redox state of methionine residues, for regulating the assembly/disassembly of MLOs. Furthermore, this mechanism based on the reversible oxidation of methionines from the LC domain of Pbp1, provides insights into how cells couple their metabolic activity to growth conditions by remodeling their MLOs to deploy an optimal response to environmental clues. Next, we will elaborate a bit on these affirmations. 


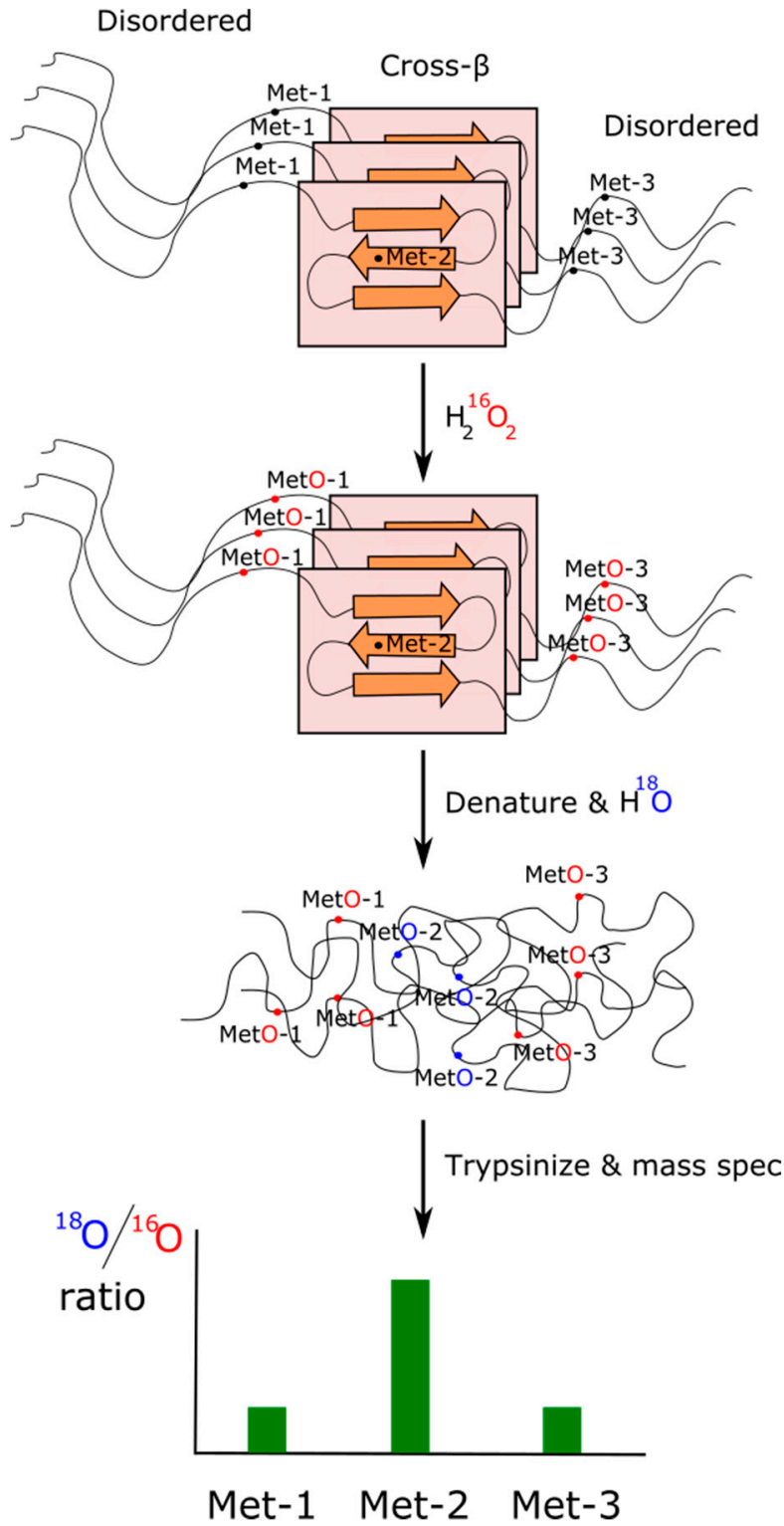

Figure 4. Schematic representation of $\mathrm{H}_{2} \mathrm{O}_{2}$-based footprinting of proteins. Three identical polypeptide chains, interacting by mean of a cross- $\beta$ structure, are represented. The $\mathrm{N}$ - and C-terminal ends of each chain are supposed to be disordered and contain accessible methionines (Met-1 and Met-3). The central $\beta$-sheets also contain methionine (Met-2) but this residue is not accessible as it is protected by the laminated $\beta$-sheets that form the cross- $\beta$ structure. The protein is initially exposed to limiting amounts of ${ }^{16} \mathrm{O}$-labeled $\mathrm{H}_{2} \mathrm{O}_{2}$, which will oxidize those methionines being accessible (MetO- 1 and MetO-3). Afterwards, the protein is denatured and oxidized to completion with ${ }^{18} \mathrm{O}-\mathrm{labeled} \mathrm{H}_{2} \mathrm{O}_{2}$, allowing the oxidation of Met-2 to MetO-2. Finally, samples are analyzed by mass spectrometry to determine the ${ }^{18} \mathrm{O} /{ }^{16} \mathrm{O}$ ratio of each methionine residue. This figure is a modification of the scheme found in the supplementary materials accompanying the paper [74].

When nutrients are scarce and fermentable substrates are absent, yeast cells resort to autophagy. Taking advantage of this fact, Yang and coworkers used a minimal medium with lactate as a non-fermentable source of carbon to carry out a screen of yeast mutants with autophagy defects. In this way, Pbp1 was identified as key regulator of autophagy. The Pbp1-deficient mutant cells exhibited a phenotype matching that of hyperactive TORC1 signaling. TORC1 is a protein kinase that coordinates cellular metabolism with environmental cues to ensure that cells grow only under favorable conditions. Thus, when active, TORC1 stimulates anabolic pathways and inhibits catabolism through repression of au- 
tophagy [168]. To explain the mechanism through which Pbp1 inhibits TORC1, which in turn stimulates autophagy, the authors proved that $\mathrm{Pbp} 1$ can directly interact with endogenous Kog1, the yeast orthologous of RAPTOR, in the presence of minimal lactate medium, but not in minimal glucose medium. Since it had been reported that, under severe heat stress, $\mathrm{Pbp} 1$ could sequester TORC1 into SGs, preventing in this way TORC1 activation [169], Yang and coworkers addressed whether Pbp1 sequestered TORC1 into SGs in response to glucose deprivation in prototrophic cells. Although they failed to localize Pbp1 into SGs, they did observe that Pbp1 exhibited a non-uniform distribution appearing as condensates through the cell, while in glucose medium Pdb1 showed a more uniform distribution through the cytoplasm. Furthermore, treatment of the yeast cells with 1,6-hexanediol, a compound used to disrupt weak hydrophobic interactions and disturb LLPS, caused a more uniform redistribution of the Ppb1 protein, further supporting the view of this protein forming biomolecular condensates within living cells [128]. Although the results obtained using 1,6-hexanediol should be interpreted with caution because this alcohol may have potential side effects on protein kinases and protein phosphatases [170], the participation of $\mathrm{Pbp} 1$ into the formation of homotypic oligomerization in vivo was further proved using complementary approaches. Thus, co-immunoprecipitation experiments showed that Pbp1 was strongly self-associated in extracts from cells grown in minimum medium, in contrast to cells grown in the presence of glucose. In line with that result, fractionation experiments showed that, in cells grown with lactate, most of the $\mathrm{Pbp} 1$ protein was detected in the insoluble fraction, suggesting that it may form large protein assemblies under such conditions. In contrast, when cells were grown in the presence of glucose, a sizeable amount of $\mathrm{Pbp} 1$ was found in the soluble fraction [128]. Overall, these observations indicate that during respiratory growth Pbp1 does not localize into SGs, but it may form biomolecular condensates that may retain TORC1, upregulating, in this way, autophagy (Figure 5). Since LC PrLDs are prevalent among proteins that are prone to phase separate, the Tu and McMnight laboratories next directed their efforts towards characterizing the role of the Pbp1 LC region in self-association and LLPS.

\section{Respiration}

\section{Fermentation}

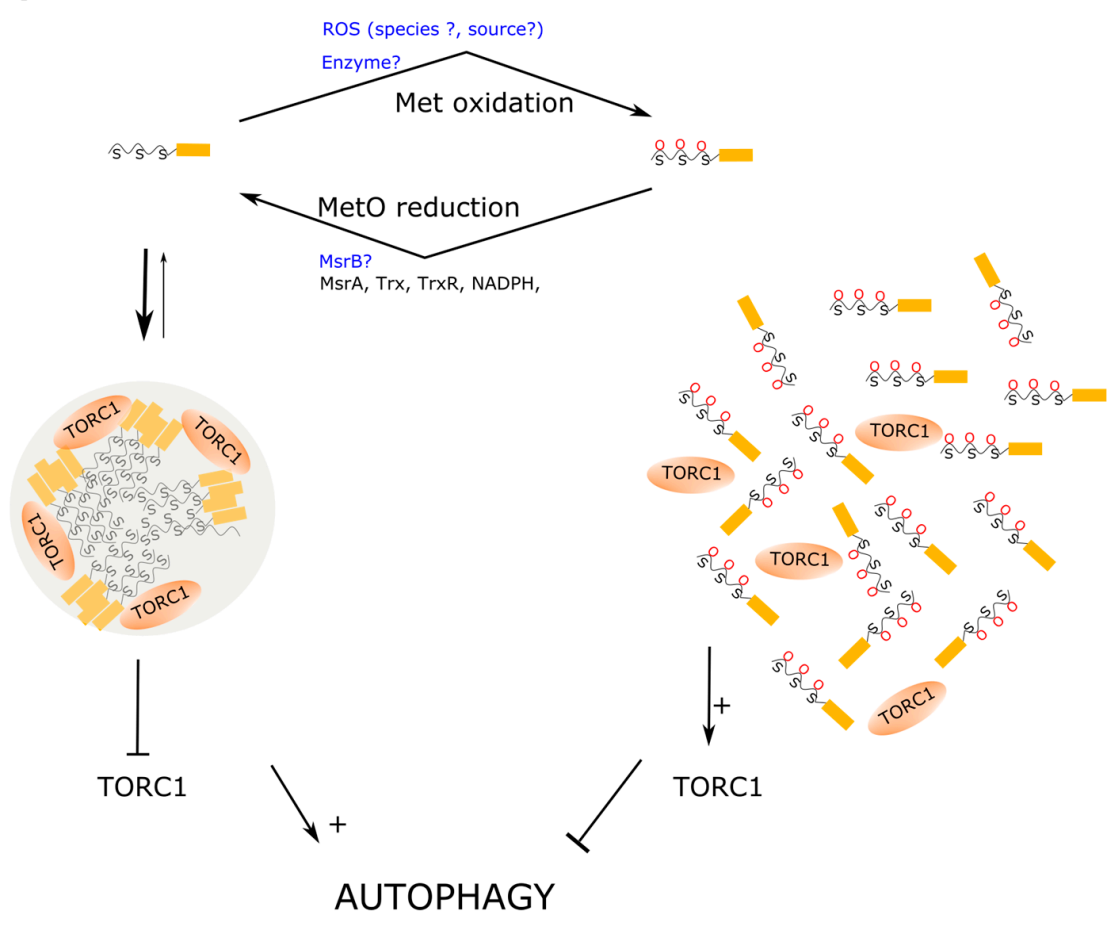

Figure 5. Metabolic status and autophagy level. The figure outlines the mechanism that coordinates the metabolic state (fermentation versus respiration) with the levels of autophagy (low and high, respectively). Key to this mechanism is the redox state of specific methionine residues of the $\mathrm{Pbp} 1$ 
protein. When these residues are in their reduced form, as methionines, the protein is competent to form biomolecular condensates that retain TORC1 in a non-soluble compartment. Since TORC1 has an inhibitory effect on autophagy, its sequestration within the condensates leads to the upregulation of autophagy. On the contrary, when the target methionines are oxidized to MetO, $\mathrm{Pbp} 1$ is unable to aggregate, and the condensates melt releasing TORC1 in the cytoplasm where it inhibits autophagy. It should be noted that within cells, methionine oxidation and MetO reduction take place through two different reactions (angled lines). That is, one reaction is not the reverse of the other, and both reactions have unrelated equilibrium constants. Labels in blue represent the aspects of the proposed mechanism that require further investigation. For instance, if ROS are the oxidants of the methionine residues, is there a particular species whose production is favored during glycolysis? Is the ROS formation compartment-dependent? Is Ppb1 oxidized in an enzyme-catalyzed manner? How relevant is, in vivo, MsrB in the reduction of oxidized Pbp1?

Upon subcloning and expression of the Pbp1 LC region, the purified recombinant protein becomes phase separated sequentially into liquid-like droplets and hydrogels. In this regard, the PrLD of Ppb1 does not differ from the LC regions of many other RNA-binding proteins that undergo phase separation. The novel and exciting aspect here is that LLPS appears to be driven and controlled by a redox-dependent mechanism that relies on the abundant methionine residues present in the PrLD of Pbp1. Thus, while the aromatic amino acid tyrosine and phenylalanine have been shown to be abundant among LC domains from diverse RNA-binding proteins prone to undergo LLPS, where they play a relevant role driving the phase separation process, leading to the formation of liquid-like droplets or hydrogels $[64,67,81]$, the $\mathrm{LC}$ region of Pbp1 is not enriched in aromatic amino acids. Instead, it contains an unusual abundance of methionine residues (Figure 3B). Furthermore, Kato and coworkers showed that $\mathrm{Pbp} 1$ methionine residues were sensitive to $\mathrm{H}_{2} \mathrm{O}_{2}$ oxidation both in vitro and in vivo. Thus, they reported that in vitro, oxidation of the methionine residues in the $\mathrm{LC}$ region to MetO led to disruption of preformed droplets, while treatment with Msrs allowed droplets to reform [73]. This redox control of condensates seems to also function in living cells as $\mathrm{Pbp} 1$ shifts into the soluble fraction of cellular extracts after treatment with $\mathrm{H}_{2} \mathrm{O}_{2}$, which inhibits autophagy, suggesting that sequestration of TORC1 by $\mathrm{Pbp} 1$ is controlled by the redox state (Figure 5). To further characterize the importance of these methionines, the authors generated and analyzed a series of mutants containing a variable number of substitutions of methionine by serine. Two methionine residues, Met614 and Met616, were revealed as important to the formation of fibrils in vitro. On the other hand, increasing the number of methionines substituted gradually reduced the ability of $\mathrm{Pbp} 1$ to induce autophagy in vivo, which correlated with an increased amount of Pbp1 in the soluble fraction of cellular extracts. Of interest, all the Met to Ser mutant combinations tested still phase-separate into droplets in vitro. However, variants containing increasing numbers of methionine substitutions significantly decreased the stability of the condensates, as the droplets melt more readily upon lowering the protein concentration [128]. Consistent with this observation, in fluorescent recovery after photobleaching experiments, the droplets formed by the Met to Ser mutants were able to recover much faster after photobleaching when compared to wild-type droplets, strongly suggesting that methionine residues in the LC domain contribute to stabilize the condensates. In particular, the segment ${ }^{591}$ MGFPMGGPSASPNPMMNGFAAGSMGMYMPFQPQPM ${ }^{625}$ within the Ppb1 PrLD, which contains eight methionine residues, including Met614 and Met616, is postulated as a key redox sensor that properly synchronizes cell physiology to the metabolic state of mitochondria [73]. Interestingly, when these eight methionine residues were changed by tyrosine instead of serine, the droplets formed in vitro were resistant to $\mathrm{H}_{2} \mathrm{O}_{2}$-driven melting. Furthermore, when this mutant was analyzed in the context of full-length $\mathrm{Pbp} 1$ within yeast cells, the $\mathrm{Pbp} 1$ protein fractionated preferentially into the non-soluble pellet fraction from cellular lysates, suggesting a gain of stability of the biomolecular condensates formed in vivo. Moreover, cells expressing this mutant version of the full-length $\mathrm{Pbp} 1$ protein also exhibited enhanced autophagy when compared to wild- 
type cells [73]. Overall, these findings point to an important role for methionine residues from the Ppb1 LC. On one side, methionine has a side chain well-endowed to stabilize protein-protein interactions, as we have discussed in previous sections. Consequently, the substitution of methionine by serine leads to destabilize the assemblies formed both in vitro and in vivo. On the other side, although the stabilizing function can be fulfilled by other amino acids, such as tyrosine and phenylalanine, methionine is unique in that its sulfur atom can be reversibly oxidized, providing, in this way, a suitable chemical mechanism to regulate the stability of the assemblies of which they form a part.

The finding of a redox sensor crafted into the LC domain of Pbp1 represents a clear step forward towards the understanding of how cells synchronize their metabolic state to the growing conditions. Nevertheless, some details remain to be fully elucidated. For instance, why does glucose fermentation lead to $\mathrm{Pbp} 1$ methionines oxidation, while aerobic respiration allows to keep these methionines in their reduced form? Although this question has not yet been specifically addressed, in the Appendix A, we review some available data with the aim to offer some ideas that may help to guide future research.

\section{5. $P a b 1$}

The poly(A) tail of mRNA is known to play multiple roles in the biogenesis, stability, and translation of messenger RNA. Many of these functions are mediated by the so-called poly(A)-binding protein (Pab1 in yeast). Like TDP-43 and ataxin-2, Pab1 is a modular protein containing RRMs and a methionine-rich LC (Figure 3C). However, while other RNA-binding proteins depend on LC domains or RNA for phase separation, the LC region of Pab1 is not required for demixing, and RNA inhibits it. Although the LC domain of Pab1 is not required for demixing, it plays a role in modulating (promoting) the process [14]. A defining feature of LC regions is that small and/or polar amino acids such as glycine, proline, serine, glutamine, and alanine are over-represented, while large and/or non-polar residues, such as arginine, cysteine, methionine, tryptophan, phenylalanine, valine, isoleucine, and leucine, are under-represented [171,172]. Therefore, the bias towards high frequencies of proline (19\% versus a yeast-proteome average $4 \%$ ) and glycine (14\% versus 5\%) observed in the Pab1 LC region fits the definition of LC domain. Somehow more surprising is the enrichment in methionine residues (10\% versus $2 \%)$. To address the potential implications of this surprising finding, Riback and coworkers assessed the influence of several mutants on phase separation. To this end, they replaced methionyl residues either by more polar amino acids (alanine) or more hydrophobic ones (isoleucine). From these experiments, they conclude that intramolecular hydrophobic interactions drive the collapse of the LC domain, which influences the demixing temperature. This parameter represents a measure of the lower critical temperature, above which the solution separates into protein-rich and protein-depleted phases. Thus, a more hydrophobic LC domain (Met to Ile) decreases this temperature by $1.6^{\circ} \mathrm{C}$, while a more polar LC domain (Met to Ala) increases it by 2.2 [14].

As we have already discussed above, Met oxidation to MetO leads to a drastic increase in polarity. Therefore, it is straightforward to hypothesize that the redox state of the methionines found at the LC of Pab1 must exert a profound influence on the temperature triggering the formation of biocondensates. Unfortunately, since the authors of the referred work were interested in $\mathrm{pH}$ and temperature as stressor stimuli, they did not assay the effect of oxidant concentrations on the phase separation of this protein. Nevertheless, awaiting results from future research, a key role for methionine residues in the coordination of LLPS of this protein in response to different stimuli can be anticipated. In other words, we would like to postulate the Pab1 segment ${ }^{433}$ MPGQFMPPMFYGVMPPRGVPFNGPNPQQMNPMGGMPKNGM ${ }^{472}$ as a redox sensor, like those previously described for Pbp1 and TDP-43 [85]. 


\section{Interconnection between Protein Translation, SGs, and Methionine Sulfoxidation}

Cells respond to stress conditions with a global reduction of protein synthesis. Phosphorylation of the alpha subunit of the eukaryotic initiation factor 2 (eIF2) is an early event of this global response. This initiation factor is a heterotrimeric GTPase composed of three subunits $(\alpha, \beta$ and $\gamma)$. This protein binds the Met-RNA ${ }_{i}{ }^{\text {Met }}$ to form the eIF2•GTP•Met$\mathrm{RNA}_{\mathrm{i}}{ }^{\text {Met }}$ ternary complex, which delivers Met-RNA ${ }_{i}{ }^{\text {Met }}$ to the small ribosomal subunit. Afterwards, the pairing between the AUG start codon and the anticodon of the Met$\mathrm{RNA}_{i}{ }^{\text {Met }}$ triggers the hydrolysis of GTP by eIF2, releasing eIF2•GDP. Since eIF2•GDP cannot bind Met-RNA ${ }_{i}{ }^{\text {Met }}$, the complex eIF2•GDP should be converted to eIF2॰GTP by the action of the exchange factor eIF2B before it can start a new initiation cycle. However, phosphorylation of eIF $2 \alpha$ in response to stressors leads to the stabilization of the complex eIF2•GDP•eIF2B, preventing the GDP-GTP exchange. As eIF2B is limiting in cells, even a small proportion of phosphorylated eIF2 $\alpha$ efficiently inhibits the rechange of eIF2 with GTP and stops, in this way, the translation initiation.

Stress-induced phosphorylation of eIF2 $\alpha$ is sufficient for SG assembly [10]. The arrest of translation initiation is accompanied by polysome disassembly, which leads to an increased concentration of uncoated mRNAs in the cytoplasm. In this way, uncoated mRNAs are available to bind to RNA-binding proteins such as G3BP1, a scaffold protein that functions as a tunable switch that triggers LLPS to assemble SGs in response to a rise in intracellular free mRNA concentrations [13]. Of interest in the context of the current review, Met222 from eIF2 $\alpha$ has been reported to suffer extensive oxidation to MetO after treating cells with $\mathrm{H}_{2} \mathrm{O}_{2}$ [173]. In a previous proteome-wide study, we addressed the potential for crosstalk between serine phosphorylation and methionine sulfoxidation. In that study, we showed that the oxidation of methionines harbored within phosphorylation motifs in response to oxidative stress is a process highly selective among stress-related proteins, including eIF2 $\alpha$, ataxin-2, and other proteins belonging to SGs [141]. Subsequent evolutionary analyses involving over 200 eukaryotic species suggested a tight relationship between sulfoxidation and phosphorylation among these SGs components. Thus, methionine and serine residues known to undergo posttranslational modification were shown to exhibit strong coevolutionary links [143]. Herein, molecular coevolution between two positions in a protein should be understood as the ability for amino acid substitution at one of these positions to affect the rates of substitution at the other position [174]. Overall, these studies point to a relationship between methionine oxidation and serine phosphorylation in proteins from SGs. However, the molecular mechanisms relating these two PTMs and the functional impact of this crosstalk on the regulation of SGs assembly/disassembly remain to be elucidated.

During stress, cells downregulate the bulk rate of protein synthesis [175]. However, transcripts bearing elements that evade eIF $2 \alpha$, e.g., possessing internal ribosome entry sites [176], are selectively translated under these stress conditions, as they produce proteins that help cells to cope with the stressful conditions. Thus, while SGs are enriched in translational arrested mRNAs released from polysomes in response to the stress stimulus, a subset of mRNAs remains actively translated and excluded from SGs. Sulfoxidation of the methionines present in the proteins encoded by this subset of transcripts seems to be an important part of the adaptive response deployed by cells to protect themselves from stress-induced damage. In this respect, a number of reports from diverse laboratories has established the view that tRNA misacylation with methionine is actively up-regulated in response to oxidative stress $[117,177,178]$. Thus, upon oxidative stress, methionyl-tRNA synthetase can catalyze the charge of non-cognate tRNA with methionine. Furthermore, the misacylated tRNA are used in translation replacing, in this way, non-methionine residues in proteins at strategic locations. There exists a body of evidence supporting the view of methionines exposed on the protein surface as endogenous antioxidants $[115,179]$. Therefore, stress-induced mismethionylation of non-methionyl tRNAs can enhance the known protective function of genetically encoded methionine residues against oxidants. The 
biological relevance of adaptive misacylation is reflected in the fact that this phenomenon is conserved in prokaryotes [180], fungi [178], and mammals [116].

\section{Concluding Remarks}

MLOs are non-stoichiometric supramolecular assemblies that contribute to cellular compartmentalization in a dynamic way. These biomolecular condensates that can be quickly assembled and disassembled in response to diverse stimuli are involved in many and diverse cellular processes. Although some of these MLOs were described more than a century ago, until recently, it has not been shown that LLPS, driven by multivalent interactions between scaffold proteins, is a fundamental organizing principle for MLOs.

Taking advantage of this physicochemical framework, laboratories around the world have been addressing how cells regulate the assembly/disassembly of these structures, the molecular composition and physical properties of the condensates, and the role played by these supramolecular structures in the cellular physiology. In the past several years, many high-impact works have been published that together allow us to draw some general principles. First, the molecular interactions stabilizing the biomolecular condensates (quinary structure), and therefore driving LLPS, are the same ones that stabilize the tertiary and quaternary structures of proteins. Hence, hydrogen bonds, salt bridges, hydrophobic effect, cation- $\pi, \pi-\pi$, domain-domain, and domain-linear motif interactions have all been described to make important contributions to the phase separation process. Not surprisingly, the ability to undergo LLPS may be a universal property of proteins provided the right conditions. However, only a selected group of proteins, referred to as scaffold proteins, have been evolutionary selected to trigger and organize the formation of a quinary structure in a regulated and biologically meaningful manner. Although the relative contribution of the different types of molecular interactions to the formation of condensates can vary widely from one protein to another, scaffold proteins share some features that are relevant for the phase separation process. Thus, many of them are RNA-binding proteins with a domain architecture. Beside one or several RRMs, these proteins often contain IDRs of low complexity that together endow the protein with a multivalent binding capacity. Indeed, the residues located in these LC regions seem to play key roles in establishing residue-residue interactions, being able to modulate the demixing process via competition between intra- and intermolecular interactions. Since a biased amino acid composition is a hallmark of LC domains, the amino acid composition of these regions can determine the type and strength of the interactions that can be stablished. In addition, many of these residues represent a target of diverse PTMs that, in a coordinated fashion, regulate the aggregation ability of the whole protein.

Although in most LC domains methionine is not a prominent amino acid, there exists a group of scaffold proteins that present LC regions with exceptionally high abundance of methionine residues. This is the case at least for TDP43, ataxin-2, and Pab1. Methionine residues can be reversibly oxidized to MetO. This modification, which drastically changes the physicochemical properties of the side chain, can be exploited to locate a redox sensor within the LC region of these proteins. In line with this view, preformed droplets of TDP43 or ataxin-2 can be melted by the oxidation of their methionines with hydrogen peroxide. Conversely, the reduction of MetO back to methionine restores the capacity of these proteins to form condensates via LLPS. The realization that LLPS can be controlled by reversible methionine oxidation, and that the methionine-rich LC domains of these proteins provide a device able to sense and respond to cellular stimuli, open fascinating possibilities for the methionine-based control of MLOs function. What we have learned from the experimental characterization of proteins, such as ataxin-2, TDP-43, and Pab1, should guide and encourage the search for similar redox sensors in other scaffold proteins. 
Funding: This research was funded by the grant UMA18-FEDERJA-149.

Institutional Review Board Statement: Not applicable.

Informed Consent Statement: Not applicable.

Acknowledgments: The author thanks Elena Aledo for the design and elaboration of the figures. The author also thanks Alicia Esteban del Valle for critical reading of the manuscript and her useful suggestions. The author also acknowledges the useful suggestions of two anonymous reviewers that have helped to improve the original manuscript.

Conflicts of Interest: The author declares no conflict of interest.

\section{Appendix A}

In the main text of the current review, we have seen that a redox sensor crafted into the LC domain of Pbp1 allows cells to coordinate their metabolic state with the growing conditions. However, there are important details about the proposed mechanisms that remain to be elucidated. This appendix revolves around the question: Why does glucose fermentation lead to $\mathrm{Pbp} 1$ methionines oxidation while aerobic respiration allows to keep these methionines in their reduced form? Since no experiments have been described that specifically address this issue, the most we can offer at this point is to jot down some ideas so that they can guide future research.

It has been observed that respiratory chain deficiencies in mammals induce mTORC1 signaling [181]. On the other hand, yeast cells exposed to exogenous $\mathrm{H}_{2} \mathrm{O}_{2}$ or treated with antimycin A (an inhibitor of the cytochrome bc1 complex) or cyanide (an inhibitor of the cytochrome c oxidase complex) each lead to the inhibition of autophagy [73,182]. In all these situations, reactive oxygen species (ROS) levels are known to be higher than those found in cells growing under physiological conditions. Regardless, they resort to aerobic fermentation or respiration. Thus, under conditions of oxidative stress, we expect $\mathrm{Pbp} 1$ methionine residues to be oxidized to MetO, which would result in the disassembly of Pbp1 condensates and the release of the sequestered TORC1 that can now exert is inhibitory effect on autophagy. Thus, what we have learned about Pbp1 and its ability to undergo phase separation in a redox-regulated way allows us to explain what we observe under oxidative stress conditions. However, the problem we face now is to explain why this set of methionines that constitutes the redox sensor of $\mathrm{Pbp} 1$ remains reduced during aerobic respiration while it becomes oxidized when the metabolic state changes to aerobic fermentation.

It is now well established that ROS, when produced in a spatiotemporally controlled form, can function as signaling molecules [183]. An obvious question to ask is whether cellular ROS levels are higher in cells grown in glucose than in cells grown in non-fermentable carbon sources. Although this possibility cannot be completely ruled out, it seems unlikely. Thus, Cabiscol and coworkers found that the levels of protein carbonyl content, an indicator of oxidative damage, in crude extracts of yeast cells grown in YPG (glycerol as carbon source) were 1.6 times higher than those in cells grown in YPD (glucose as carbon source) [184]. Nevertheless, we must bear in mind that different methods of estimating ROS levels can yield different results. In this respect, Maslanka et al. reported that, when the ROS levels were assessed using the probe dihydroethidium, which is oxidized by superoxide anion to fluorescent ethidium, the yeast cultivated in glycerol medium showed lower ROS levels than those cells grown in glucose [185]. However, when these same authors used another probe, $\mathrm{H}_{2}$ DCF-DA, which is not substrate-specific, to evaluate the ROS content, then the highest level of ROS was observed in cells grown in glycerol.

This mixture of somewhat conflicting results illustrates the complexity of finding the physiological Pbp1 oxidant. In addition, spatial compartmentalization of ROS production adds a further layer of complexity to our problem [186,187]. In other words, to conveniently oxidize Ppb1 methionyl residues in response to metabolic changes, it may be critical to produce ROS in the right compartment rather than increase total cellular ROS levels. Interestingly, when yeast mitochondria are incubated with either succinate or 
malate, low levels of hydrogen peroxide are produced. However, if exogenous NADH is added, larger amounts of $\mathrm{H}_{2} \mathrm{O}_{2}$ are produced at the external NADH dehydrogenases [188]. Unlike mammalian mitochondria, yeast mitochondria oxidize cytosolic NADH directly via two external NADH dehydrogenase, Nde1 and Nde2, which are located at the inner mitochondrial membrane with their active sites facing the intermembrane space [189]. Since the mitochondrial inner membrane is impermeable to $\mathrm{NADH}$, they have been proposed to oxidize cytosolic NADH produced via glycolysis [190]. On the other hand, yeast cells can also produce $\mathrm{H}_{2} \mathrm{O}_{2}$ via a NADPH oxidase-like enzyme named Yno1p. Thus, it has been shown that $\mathrm{Yno1}$ p-derived $\mathrm{H}_{2} \mathrm{O}_{2}$ regulates processes controlled by MAPK pathways [191]. In summary, the oxidation of the Pbp1 LC region by a specific oxidant produced in a controlled way is a possibility that remains to be explored.

An alternative, although highly speculative as there is currently no direct evidence to support it, is that methionine residues from the $\mathrm{Pbp} 1$ redox sensor may be oxidized in a highly specific manner through an enzyme-catalyzed reaction. Indeed, flavin-containing monooxygenases (FMOs) have been shown to oxidize protein-bound methionines using molecular oxygen and NADPH as co-substrates [192]. In animals, MICALs, a family of FMO enzymes [193], have been characterized as NADPH-dependent methionine sulfoxidase exhibiting a high substrate specificity, and as being involved in the control of F-acting assembling/disassembling [121-123] as well as in the regulation of CaMKII [125]. In the fungus Aspergillus nidulans, a FMO termed FmoB has been identified as responsible for the inactivation of the transcription factor NirA via oxidation of a single methionine residue in its nuclear export signal [120]. Therefore, although the currently characterized FMO from S. cerevisiae can oxidize thiol-compounds but not methionine [194], the existence of enzyme-catalyzed methionine oxidations in yeast cannot be ruled out.

Hitherto, we have focused our attention on the oxidation of the methionines forming part of the redox sensor from the Pbp1 PrLD. However, it is important to realize that what is relevant for the homotypic aggregation of $\mathrm{Pbp} 1$ is the stationary redox status of these methionines, which is the result of the balance between two different reactions: methionine oxidation, which has been discussed above, and MetO reduction, which will be considered next.

Methionine sulfoxide has an asymmetric sulfur center. Thus, when protein-bound methionine residues are oxidized by ROS, generally a racemate of two diasteroisomers, methionine-S-sulfoxide (Met-S-SO) and methionine- $R$-sulfoxide (Met-R-SO), is formed. However, different oxidants (different oxygen reactive species) may exhibit different grades of stereospecificity [195]. In any case, these two stereoisomers can be reduced back to methionine by two evolutionarily unrelated stereospecific enzymes designated as MsrA and MsrB, respectively [142,196]. The budding yeast S. cerevisiae has single MsrA and MsrB genes. Thus, in this organism, MsrA is the main enzyme that reduces Met-S-SO residues and its primarily detected in the cytoplasm, while MsrB is responsible for reducing Met-R-SO and is mostly found in mitochondria [197]. Interestingly, MsrA, despite mainly being a cytosolic enzyme, has been proven essential to maintain functional mitochondria. Thus, deletion mutants lacking this isoform show the same levels of mitochondria, but these mitochondria were not respiration-competent as judged by a low accumulation of the MitoRed marker (17\% with respect to wild-type), which selectively accumulates within mitochondria able to maintain their membrane potential [197]. This result is coherent with the working hypothesis that the lack of MsrA activity in the cytoplasm of these mutant cells prevents the reduction of MetO from Pbp1, which, in turn, should block the condensation of this protein when the cell shifts towards a respiration-dependent metabolic state. If this is the case, an easy to test prediction is that these mutants must exhibit hyperactive TORC1 signaling, including depressed autophagy, even during respiratory growth, which would explain the fact that the number of mitochondria is maintained in the mutants, while these mitochondria have lost their functionality. 


\section{References}

1. Gamble, J.G.; Lehninger, A.L. Transport of ornithine and citrulline across the mitochondrial membrane. J. Biol. Chem. 1973, 248, 610-618. [CrossRef]

2. Cambronne, X.A.; Kraus, W.L. Location, Location, Location: Compartmentalization of NAD+ Synthesis and Functions in Mammalian Cells. Trends Biochem. Sci. 2020, 45, 858-873. [CrossRef]

3. Gabaldón, T.; Pittis, A.A. Origin and evolution of metabolic sub-cellular compartmentalization in eukaryotes. Biochimie 2015, 119, 262-268. [CrossRef]

4. Greening, C.; Lithgow, T. Formation and function of bacterial organelles. Nat. Rev. Microbiol. 2020, 18, 677-689. [CrossRef]

5. Pederson, T. The nucleolus. Cold Spring Harb. Perspect. Biol. 2011, 3, a00638. [CrossRef] [PubMed]

6. Gall, J.G.; Bellini, M.; Wu, Z.; Murphy, C. Assembly of the nuclear transcription and processing machinery: Cajal bodies (coiled bodies) and transcriptosomes. Mol. Biol. Cell 1999, 10, 4385-4402. [CrossRef] [PubMed]

7. Galganski, L.; Urbanek, M.O.; Krzyzosiak, W.J. Nuclear speckles: Molecular organization, biological function and role in disease. Nucleic Acids Res. 2017, 45, 10350-10368. [CrossRef]

8. Li, Z.F.; Lam, Y.W. A new rapid method for isolating nucleoli. In Methods in Molecular Biology; Humana Press: New York, NY, USA, 2015; Volume 1228, pp. 35-42. ISBN 9781493916795.

9. Franzmann, T.M.; Jahnel, M.; Pozniakovsky, A.; Mahamid, J.; Holehouse, A.S.; Nüske, E.; Richter, D.; Baumeister, W.; Grill, S.W.; Pappu, R.V.; et al. Phase separation of a yeast prion protein promotes cellular fitness. Science 2018, 359, eaao5654. [CrossRef] [PubMed]

10. Ivanov, P.; Kedersha, N.; Anderson, P. Stress granules and processing bodies in translational control. Cold Spring Harb. Perspect. Biol. 2019, 11, a032813. [CrossRef] [PubMed]

11. Pancsa, R.; Vranken, W.; Mészáros, B. Computational resources for identifying and describing proteins driving liquid-liquid phase separation. Brief. Bioinform. 2021, bbaa408. [CrossRef] [PubMed]

12. Banani, S.F.; Lee, H.O.; Hyman, A.A.; Rosen, M.K. Biomolecular condensates: Organizers of cellular biochemistry. Nat. Rev. Mol. Cell Biol. 2017, 18, 285-298. [CrossRef]

13. Yang, P.; Mathieu, C.; Kolaitis, R.M.; Zhang, P.; Messing, J.; Yurtsever, U.; Yang, Z.; Wu, J.; Li, Y.; Pan, Q.; et al. G3BP1 Is a Tunable Switch that Triggers Phase Separation to Assemble Stress Granules. Cell 2020, 181, 325-345.e28. [CrossRef]

14. Riback, J.A.; Katanski, C.D.; Kear-Scott, J.L.; Pilipenko, E.V.; Rojek, A.E.; Sosnick, T.R.; Drummond, D.A. Stress-Triggered Phase Separation Is an Adaptive, Evolutionarily Tuned Response. Cell 2017, 168, 1028-1040.e19. [CrossRef]

15. Abbondanzieri, E.A.; Meyer, A.S. More than just a phase: The search for membraneless organelles in the bacterial cytoplasm. Curr. Genet. 2019, 65, 691-694. [CrossRef]

16. Cohan, M.C.; Pappu, R.V. Making the Case for Disordered Proteins and Biomolecular Condensates in Bacteria. Trends Biochem. Sci. 2020, 45, 668-680. [CrossRef] [PubMed]

17. Azaldegui, C.A.; Vecchiarelli, A.G.; Biteen, J.S. The Emergence of Phase Separation as an Organizing Principle in Bacteria. Biophys. J. 2020, 120, 1123-1138. [CrossRef]

18. Muthunayake, N.S.; Tomares, D.T.; Childers, W.S.; Schrader, J.M. Phase-separated bacterial ribonucleoprotein bodies organize mRNA decay. Wiley Interdiscip. Rev. RNA 2020, 11, 1-26. [CrossRef]

19. Emenecker, R.J.; Holehouse, A.S.; Strader, L.C. Emerging Roles for Phase Separation in Plants. Dev. Cell 2020, 55, 69-83. [CrossRef]

20. Xu, X.; Zheng, C.; Lu, D.; Song, C.; Zhang, L. Phase separation in plants: New insights into cellular compartmentalization. J. Integr. Plant Biol. 2021. [CrossRef]

21. Nikolic, J.; Le Bars, R.; Lama, Z.; Scrima, N.; Lagaudrière-Gesbert, C.; Gaudin, Y.; Blondel, D. Negri bodies are viral factories with properties of liquid organelles. Nat. Commun. 2017, 8, 1-12. [CrossRef]

22. Guseva, S.; Milles, S.; Jensen, M.R.; Salvi, N.; Kleman, J.P.; Maurin, D.; Ruigrok, R.W.H.; Blackledge, M. Measles virus nucleoAnd phosphoproteins form liquid-like phase-separated compartments that promote nucleocapsid assembly. Sci. Adv. 2020, 6, 1-12. [CrossRef]

23. Brocca, S.; Grandori, R.; Longhi, S.; Uversky, V. Liquid-liquid phase separation by intrinsically disordered protein regions of viruses: Roles in viral life cycle and control of virus-host interactions. Int. J. Mol. Sci. 2020, 21, 9045. [CrossRef] [PubMed]

24. Zhou, Y.; Su, J.M.; Samuel, C.E.; Ma, D. Measles virus forms inclusion bodies with properties of liquid organelles. J. Virol. 2019, 93, 1-18. [CrossRef]

25. Oparin, A. Proiskhozhdenie Zhizny; Izd. Moskovhii RabochiI: Moscow, Russia, 1924; ISBN 9781351478007.

26. Gruebele, M. Protein folding and surface interaction phase diagrams in vitro and in cells. FEBS Lett. 2021, 595, 1267-1274. [CrossRef]

27. Flory, P.J. Principles of Polymer Chemistry; Cornell University Press: Ithaca, NY, USA, 1953; ISBN 0801401348.

28. Lin, Y.H.; Forman-Kay, J.D.; Chan, H.S. Theories for Sequence-Dependent Phase Behaviors of Biomolecular Condensates. Biochemistry 2018, 57, 2499-2508. [CrossRef] [PubMed]

29. Zaslavsky, B.Y.; Ferreira, L.A.; Uversky, V.N. Driving forces of liquid-liquid phase separation in biological systems. Biomolecules 2019, 9, 473. [CrossRef] [PubMed]

30. Zaslavsky, B.Y.; Uversky, V.N. In Aqua Veritas: The Indispensable yet Mostly Ignored Role of Water in Phase Separation and Membrane-less Organelles. Biochemistry 2018, 57, 2437-2451. [CrossRef] [PubMed] 
31. Olsen, B.R.; Svenneby, G.; Kvamme, E.; Tveit, B.; Eskeland, T. Formation and ultrastructure of enzymically active polymers of pig renal glutaminase. J. Mol. Biol. 1970, 52, 239-245. [CrossRef]

32. Meredith, M.J.; Lane, M.D. Acetyl-CoA carboxylase. Evidence for polymeric filament to protomer transition in the intact avian liver cell. J. Biol. Chem. 1978, 253, 3381-3383. [CrossRef]

33. Beaty, N.B.; Lane, M.D. The polymerization of acetyl-CoA carboxylase. J. Biol. Chem. 1983, 258, 13051-13055. [CrossRef]

34. Aledo, J.C.; De Pedro, E.; Gömez-Fabre, P.M.; De Castro, I.N.; Márquez, J. Submitochondrial localization and membrane topography of Ehrlich ascitic tumour cell glutaminase. Biochim. Biophys. Acta Biomembr. 1997, 1323, 173-184. [CrossRef]

35. Aledo, J.C. Glutamine breakdown in rapidly dividing cells: Waste or investment? BioEssays 2004, 26, 778-785. [CrossRef]

36. Olalla, L.; Gutiérrez, A.; Campos, J.A.; Khan, Z.U.; Alonso, F.J.; Segura, J.A.; Márquez, J.; Carlos Aledo, J. Nuclear localization of L-type glutaminase in mammalian brain. J. Biol. Chem. 2002, 277, 38939-38944. [CrossRef]

37. Ferreira, A.P.S.; Cassago, A.; De Almeida Gonçalves, K.; Dias, M.M.; Adamoski, D.; Ascenção, C.F.R.; Honorato, R.V.; De Oliveira, J.F.; Ferreira, I.M.; Fornezari, C.; et al. Active glutaminase $C$ self-assembles into a supratetrameric oligomer that can be disrupted by an allosteric inhibitor. J. Biol. Chem. 2013, 288, 28009-28020. [CrossRef]

38. Ferreira, I.M.; Quesñay, J.E.N.; Bastos, A.C.; Rodrigues, C.T.; Vollmar, M.; Krojer, T.; Strain-Damerell, C.; Burgess-Brown, N.A.; von Delft, F.; Yue, W.W.; et al. Structure and activation mechanism of the human liver-type glutaminase GLS2. Biochimie 2021, 185, 96-104. [CrossRef]

39. Wang, Y.; Lomakin, A.; Kanai, S.; Alex, R.; Benedek, G.B. Liquid-Liquid Phase Separation in Oligomeric Peptide Solutions. Langmuir 2017, 33, 7715-7721. [CrossRef]

40. Knull, H.R. Association of glycolytic enzymes with particulate fractions from nerve endings. Biochim. Biophys. Acta 1978, 522, 1-9. [CrossRef]

41. Wilson, J.E. Ambiquitous enzymes: Variation in intracellular distribution as a regulatory mechanism. Trends Biochem. Sci. 1978, 3, 124-125. [CrossRef]

42. Wilson, J.E. Brain Hexokinase. J. Biol. Chem. 1968, 243, 3640-3647. [CrossRef]

43. Clarke, F.M.; Masters, C.J. On the association of glycolytic components in skeletal muscle extracts. Biochim. Biophys. Acta 1974, 358, 193-207. [CrossRef]

44. Srere, P.; Knull, H. Location-location-location. Trends Biochem. Sci. 1998, 23, 319-320. [CrossRef]

45. Robinson, J.B.; Srere, P.A. Organization of Krebs tricarboxylic acid cycle enzymes in mitochondria. J. Biol. Chem. 1985, 260, 10800-10805. [CrossRef]

46. Menard, L.; Maughan, D.; Vigoreaux, J. The structural and functional coordination of glycolytic enzymes in muscle: Evidence of a metabolon? Biology 2014, 3, 623-644. [CrossRef] [PubMed]

47. Srere, P.A. The metabolon. Trends Biochem. Sci. 1985, 10, 109-110. [CrossRef]

48. Jang, S.R.; Xuan, Z.; Lagoy, R.C.; Jawerth, L.M.; Gonzalez, I.J.; Singh, M.; Prashad, S.; Kim, H.S.; Patel, A.; Albrecht, D.R.; et al. Phosphofructokinase relocalizes into subcellular compartments with liquid-like properties in vivo. Biophys. J. 2021, 120, 1170-1186. [CrossRef]

49. Narayanaswamy, R.; Levy, M.; Tsechansky, M.; Stovall, G.M.; O'Connell, J.D.; Mirrielees, J.; Ellington, A.D.; Marcotte, E.M. Widespread reorganization of metabolic enzymes into reversible assemblies upon nutrient starvation. Proc. Natl. Acad. Sci. USA 2009, 106, 10147-10152. [CrossRef] [PubMed]

50. Dumetz, A.C.; Chockla, A.M.; Kaler, E.W.; Lenhoff, A.M. Protein phase behavior in aqueous solutions: Crystallization, liquidliquid phase separation, gels, and aggregates. Biophys. J. 2008, 94, 570-583. [CrossRef]

51. Uversky, V.N.; Finkelstein, A.V. Life in phases: Intra-and inter-molecular phase transitions in protein solutions. Biomolecules 2019, 9, 842. [CrossRef]

52. Gomes, E.; Shorter, J. The molecular language of membraneless organelles. J. Biol. Chem. 2019, 294, 7115-7127. [CrossRef]

53. Alberti, S.; Gladfelter, A.; Mittag, T. Considerations and Challenges in Studying Liquid-Liquid Phase Separation and Biomolecular Condensates. Cell 2019, 176, 419-434. [CrossRef]

54. Milin, A.N.; Deniz, A.A. Reentrant Phase Transitions and Non-Equilibrium Dynamics in Membraneless Organelles. Biochemistry 2018, 57, 2470-2477. [CrossRef] [PubMed]

55. Rai, A.K.; Chen, J.X.; Selbach, M.; Pelkmans, L. Kinase-controlled phase transition of membraneless organelles in mitosis. Nature 2018, 559, 211-216. [CrossRef] [PubMed]

56. Smith, C.; Spector, L. Redistribution of U-snRNPs during Mitosis. Exp. Cell Res. 1986, 163, 87-94.

57. Sivan, G.; Kedersha, N.; Elroy-Stein, O. Ribosomal Slowdown Mediates Translational Arrest during Cellular Division. Mol. Cell. Biol. 2007, 27, 6639-6646. [CrossRef]

58. Henninger, J.E.; Oksuz, O.; Shrinivas, K.; Sagi, I.; LeRoy, G.; Zheng, M.M.; Andrews, J.O.; Zamudio, A.V.; Lazaris, C.; Hannett, N.M.; et al. RNA-Mediated Feedback Control of Transcriptional Condensates. Cell 2021, 184, 207-225.e24. [CrossRef]

59. Castello, A.; Fischer, B.; Eichelbaum, K.; Horos, R.; Beckmann, B.M.; Strein, C.; Davey, N.E.; Humphreys, D.T.; Preiss, T.; Steinmetz L.M.; et al. Insights into RNA Biology from an Atlas of Mammalian mRNA-Binding Proteins. Cell 2012, 149, 1393-1406. [CrossRef]

60. Grosberg, A.Y.; Nguyen, T.T.; Shklovskii, B.I. Colloquium: The physics of charge inversion in chemical and biological systems. Rev. Mod. Phys. 2002, 74, 329-345. [CrossRef] 
61. Zhang, F.; Skoda, M.W.A.; Jacobs, R.M.J.; Zorn, S.; Martin, R.A.; Martin, C.M.; Clark, G.F.; Weggler, S.; Hildebrandt, A.; Kohlbacher, O.; et al. Reentrant condensation of proteins in solution induced by multivalent counterions. Phys. Rev. Lett. 2008, 101, 3-6. [CrossRef]

62. Li, P.; Banjade, S.; Cheng, H.C.; Kim, S.; Chen, B.; Guo, L.; Llaguno, M.; Hollingsworth, J.V.; King, D.S.; Banani, S.F.; et al. Phase transitions in the assembly of multivalent signalling proteins. Nature 2012, 483, 336-340. [CrossRef]

63. Harrison, A.F.; Shorter, J. RNA-binding proteins with prion-like domains in health and disease. Biochem. J. 2017, 474, 1417-1438. [CrossRef] [PubMed]

64. Wang, J.; Choi, J.M.; Holehouse, A.S.; Lee, H.O.; Zhang, X.; Jahnel, M.; Maharana, S.; Lemaitre, R.; Pozniakovsky, A.; Drechsel, D.; et al. A Molecular Grammar Governing the Driving Forces for Phase Separation of Prion-like RNA Binding Proteins. Cell 2018, 174, 688-699.e16. [CrossRef] [PubMed]

65. Feng, Z.; Chen, X.; Wu, X.; Zhang, M. Formation of biological condensates via phase separation: Characteristics, analytical methods, and physiological implications. J. Biol. Chem. 2019, 294, 14823-14835. [CrossRef]

66. Dignon, G.L.; Best, R.B.; Mittal, J. Biomolecular Phase Separation: From Molecular Driving Forces to Macroscopic Properties. Annu. Rev. Phys. Chem. 2020, 71, 53-75. [CrossRef]

67. Lin, Y.; Currie, S.L.; Rosen, M.K. Intrinsically disordered sequences enable modulation of protein phase separation through distributed tyrosine motifs. J. Biol. Chem. 2017, 292, 19110-19120. [CrossRef]

68. Vernon, R.M.C.; Chong, P.A.; Tsang, B.; Kim, T.H.; Bah, A.; Farber, P.; Lin, H.; Forman-Kay, J.D. Pi-Pi contacts are an overlooked protein feature relevant to phase separation. Elife 2018, 7, e31486. [CrossRef]

69. Kumar, K.; Woo, S.M.; Siu, T.; Cortopassi, W.A.; Duarte, F.; Paton, R.S. Cation- $\pi$ interactions in protein-ligand binding: Theory and data-mining reveal different roles for lysine and arginine. Chem. Sci. 2018, 9, 2655-2665. [CrossRef]

70. Qamar, S.; Wang, G.Z.; Randle, S.J.; Ruggeri, F.S.; Varela, J.A.; Lin, J.Q.; Phillips, E.C.; Miyashita, A.; Williams, D.; Ströhl, F.; et al. FUS Phase Separation Is Modulated by a Molecular Chaperone and Methylation of Arginine Cation- $\pi$ Interactions. Cell 2018, 173, 720-734.e15. [CrossRef]

71. Nott, T.J.; Petsalaki, E.; Farber, P.; Jervis, D.; Fussner, E.; Plochowietz, A.; Craggs, T.D.; Bazett-Jones, D.P.; Pawson, T.; Forman-Kay, J.D.; et al. Phase Transition of a Disordered Nuage Protein Generates Environmentally Responsive Membraneless Organelles. Mol. Cell 2015, 57, 936-947. [CrossRef] [PubMed]

72. Murthy, A.C.; Dignon, G.L.; Kan, Y.; Zerze, G.H.; Parekh, S.H.; Mittal, J.; Fawzi, N.L. Molecular interactions underlying liquid-liquid phase separation of the FUS low-complexity domain. Nat. Struct. Mol. Biol. 2019, 26, 637-648. [CrossRef]

73. Kato, M.; Yang, Y.S.; Sutter, B.M.; Wang, Y.; McKnight, S.L.; Tu, B.P. Redox State Controls Phase Separation of the Yeast Ataxin2 Protein via Reversible Oxidation of Its Methionine-Rich Low-Complexity Domain. Cell 2019, 177, 711-721.e8. [CrossRef] [PubMed]

74. Lin, Y.; Zhou, X.; Kato, M.; Liu, D.; Ghaemmaghami, S.; Tu, B.P.; McKnight, S.L. Redox-mediated regulation of an evolutionarily conserved cross- $\beta$ structure formed by the TDP43 low complexity domain. Proc. Natl. Acad. Sci. USA 2020, 117, 28727-28734. [CrossRef]

75. Valley, C.C.; Cembran, A.; Perlmutter, J.D.; Lewis, A.K.; Labello, N.P.; Gao, J.; Sachs, J.N. The methionine-aromatic motif plays a unique role in stabilizing protein structure. J. Biol. Chem. 2012, 287, 34979-34991. [CrossRef]

76. Aledo, J.C.; Cantón, F.R.; Veredas, F.J. Sulphur atoms from methionines interacting with aromatic residues are less prone to oxidation. Sci. Rep. 2015, 5, 16955. [CrossRef]

77. Uversky, V.N. Intrinsically disordered proteins in overcrowded milieu: Membrane-less organelles, phase separation, and intrinsic disorder. Curr. Opin. Struct. Biol. 2017, 44, 18-30. [CrossRef] [PubMed]

78. Oldfield, C.J.; Dunker, A.K. Intrinsically disordered proteins and intrinsically disordered protein regions. Annu. Rev. Biochem. 2014, 83, 553-584. [CrossRef]

79. Das, R.K.; Ruff, K.M.; Pappu, R.V. Relating sequence encoded information to form and function of intrinsically disordered proteins. Curr. Opin. Struct. Biol. 2015, 32, 102-112. [CrossRef]

80. Uversky, V.N. Protein intrinsic disorder-based liquid-liquid phase transitions in biological systems: Complex coacervates and membrane-less organelles. Adv. Colloid Interface Sci. 2017, 239, 97-114. [CrossRef]

81. Xiang, S.; Kato, M.; Wu, L.; Lin, Y.; Ding, M.; Zhang, Y.; Yu, Y.; McKnight, S. The LC Domain of hnRNAPA2 Adopts Similar Conformations in Hydrogel Polymers, Liquid-like Droplets and Nuclei. Cell 2015, 163, 829-839. [CrossRef]

82. Murray, D.T.; Kato, M.; Lin, Y.; Thurber, K.R.; Hung, I.; McKnight, S.L.; Tycko, R. Structure of FUS Protein Fibrils and Its Relevance to Self-Assembly and Phase Separation of Low-Complexity Domains. Cell 2017, 171, 615-627.e16. [CrossRef]

83. Nelson, R.; Sawaya, M.R.; Balbirnie, M.; Madsen, A.; Riekel, C.; Grothe, R.; Eisenberg, D. Structure of the cross- $\beta$ spine of amyloid-like fibrils. Nature 2005, 435, 773-778. [CrossRef] [PubMed]

84. Hughes, M.P.; Sawaya, M.R.; Boyer, D.R.; Goldschmidt, L.; Rodriguez, J.A.; Cascio, D.; Chong, L.; Gonen, T.; Eisenberg, D.S. Atomic structures of low-complexity protein segments reveal kinked b sheets that assemble networks. Science 2018, 359, 698-701. [CrossRef]

85. Kato, M.; Tu, B.P.; McKnight, S.L. Redox-mediated regulation of low complexity domain self-association. Curr. Opin. Genet. Dev. 2021, 67, 111-118. [CrossRef] [PubMed]

86. Minguez, P.; Parca, L.; Diella, F.; Mende, D.R.; Kumar, R.; Helmer-Citterich, M.; Gavin, A.C.; Van Noort, V.; Bork, P. Deciphering a global network of functionally associated post-translational modifications. Mol. Syst. Biol. 2012, 8, 1-14. [CrossRef] [PubMed] 
87. Beltrao, P.; Bork, P.; Krogan, N.J.; Van Noort, V. Evolution and functional cross-talk of protein post-translational modifications. Mol. Syst. Biol. 2013, 9, 1-13. [CrossRef] [PubMed]

88. Smith, L.M.; Kelleher, N.L.; The Consortium for Top Down Proteomics. Proteoform: A single term describing protein complexity. Nat. Methods 2013, 10, 186-187. [CrossRef]

89. Creixell, P.; Linding, R. Cells, shared memory and breaking the PTM code. Mol. Syst. Biol. 2012, 8, 1-2. [CrossRef]

90. Bah, A.; Forman-Kay, J.D. Modulation of intrinsically disordered protein function by post-translational modifications. J. Biol. Chem. 2016, 291, 6696-6705. [CrossRef]

91. Collins, M.O.; Yu, L.; Campuzano, I.; Grant, S.G.N.; Choudhary, J.S. Phosphoproteomic analysis of the mouse brain cytosol reveals a predominance of protein phosphorylation in regions of intrinsic sequence diorder. Mol. Cell. Proteom. 2008, 7, 1331-1348. [CrossRef]

92. Dang, M.; Lim, L.; Kang, J.; Song, J. ATP biphasically modulates LLPS of TDP-43 PLD by specifically binding arginine residues. Commun. Biol. 2021, 4, 1-12. [CrossRef]

93. Ryan, V.H.; Dignon, G.L.; Zerze, G.H.; Chabata, C.V.; Silva, R.; Conicella, A.E.; Amaya, J.; Burke, K.A.; Mittal, J.; Fawzi, N.L. Mechanistic View of hnRNPA2 Low-Complexity Domain Structure, Interactions, and Phase Separation Altered by Mutation and Arginine Methylation. Mol. Cell 2018, 69, 465-479.e7. [CrossRef]

94. Hofweber, M.; Hutten, S.; Bourgeois, B.; Spreitzer, E.; Niedner-Boblenz, A.; Schifferer, M.; Ruepp, M.D.; Simons, M.; Niessing, D.; Madl, T.; et al. Phase Separation of FUS Is Suppressed by Its Nuclear Import Receptor and Arginine Methylation. Cell 2018, 173, 706-719.e13. [CrossRef]

95. Bedford, M.T.; Clarke, S.G. Protein Arginine Methylation in Mammals: Who, What, and Why. Mol. Cell 2009, 33, 1-13. [CrossRef] [PubMed]

96. Begovich, K.; Vu, A.Q.; Yeo, G.; Wilhelm, J.E. Conserved metabolite regulation of stress granule assembly via AdoMet. J. Cell Biol. 2020, 219, e201904141. [CrossRef]

97. Hofweber, M.; Dormann, X.D. Friend or foe-Post-translational modifications as regulators of phase separation and RNP granule dynamics. J. Biol. Chem. 2019, 294, 7137-7150. [CrossRef] [PubMed]

98. Tanikawa, C.; Ueda, K.; Suzuki, A.; Iida, A.; Nakamura, R.; Atsuta, N.; Tohnai, G.; Sobue, G.; Saichi, N.; Momozawa, Y.; et al. Citrullination of RGG Motifs in FET Proteins by PAD4 Regulates Protein Aggregation and ALS Susceptibility. Cell Rep. 2018, 22, 1473-1483. [CrossRef]

99. Witalisom, E.; Thompson, R.; Hofseth, L. Protein Arginine Deiminases and Associated Cirtullination. Curr. Drug Targets 2015, 16, 700-710. [CrossRef]

100. Fackelmayer, F.O. Protein arginine methyltransferases: Guardians of the Arg? Trends Biochem. Sci. 2005, 30, 666-671. [CrossRef]

101. Mandell, D.J.; Chorny, I.; Groban, E.S.; Wong, S.E.; Levine, E.; Rapp, C.S.; Jacobson, M.P. Strengths of hydrogen bonds involving phosphorylated amino acid side chains. J. Am. Chem. Soc. 2007, 129, 820-827. [CrossRef]

102. Andrew, C.D.; Warwicker, J.; Jones, G.R.; Doig, A.J. Effect of phosphorylation on $\alpha$-helix stability as a function of position Biochemistry 2002, 41, 1897-1905. [CrossRef] [PubMed]

103. Suetsugu, S.; Miki, H.; Takenawa, T. Spatial and temporal regulation of actin polymerization for cytoskeleton formation through Arp2/3 complex and WASP/WAVE proteins. Cell Motil. Cytoskelet. 2002, 51, 113-122. [CrossRef] [PubMed]

104. Ambadipudi, S.; Biernat, J.; Riedel, D.; Mandelkow, E.; Zweckstetter, M. Liquid-liquid phase separation of the microtubule-binding repeats of the Alzheimer-related protein Tau. Nat. Commun. 2017, 8, 1-13. [CrossRef]

105. Carlomagno, Y.; Chung, D.; Eun, C.; Yue, M.; Castanedes-Casey, M.; Madden, B.J.; Dunmore, J.; Tong, J.; DeTure, M.; Dickson, D.W.; et al. An Acetylation-phosphorylation switch that regulates tau aggregation propensity and function. J. Biol. Chem. 2017, 292, 15277-15286. [CrossRef]

106. Ferreon, J.C.; Jain, A.; Choi, K.J.; Tsoi, P.S.; Mackenzie, K.R.; Jung, S.Y.; Ferreon, A.C. Acetylation disfavors tau phase separation. Int. J. Mol. Sci. 2018, 19, 1360. [CrossRef] [PubMed]

107. Saito, M.; Hess, D.; Eglinger, J.; Fritsch, A.W.; Kreysing, M.; Weinert, B.T.; Choudhary, C.; Matthias, P. Acetylation of intrinsically disordered regions regulates phase separation. Nat. Chem. Biol. 2019, 15, 51-61. [CrossRef] [PubMed]

108. Kwon, S.; Zhang, Y.; Matthias, P. The deacetylase HDAC6 is a novel critical component of stress granules involved in the stress response. Genes Dev. 2007, 21, 3381-3394. [CrossRef] [PubMed]

109. Wang, A.C.; Jensen, E.H.; Rexach, J.E.; Vinters, H.V.; Hsieh-Wilson, L.C. Loss of O-GlcNAc glycosylation in forebrain excitatory neurons induces neurodegeneration. Proc. Natl. Acad. Sci. USA 2016, 113, 15120-15125. [CrossRef]

110. Roth, S.; Khalaila, I. The effect of O-GlcNAcylation on hnRNP A1 translocation and interaction with transportin1. Exp. Cell Res. 2017, 350, 210-217. [CrossRef]

111. Pamplona, R.; Barja, G. Mitochondrial oxidative stress, aging and caloric restriction: The protein and methionine connection. Biochim. Biophys. Acta Bioenerg. 2006, 1757, 496-508. [CrossRef]

112. Ruiz, M.C.; Ayala, V.; Portero-Otín, M.; Requena, J.R.; Barja, G.; Pamplona, R. Protein methionine content and MDA-lysine adducts are inversely related to maximum life span in the heart of mammals. Mech. Ageing Dev. 2005, 126, 1106-1114. [CrossRef]

113. Stadtman, E.R.; Van Remmen, H.; Richardson, A.; Wehr, N.B.; Levine, R.L. Methionine oxidation and aging. Biochim. Biophys. Acta Proteins Proteomics 2005, 1703, 135-140. [CrossRef]

114. Reeg, S.; Grune, T. Protein Oxidation in Aging: Does It Play a Role in Aging Progression? Antioxid. Redox Signal. 2015, 23, 239-255. [CrossRef] 
115. Levine, R.L.; Mosoni, L.; Berlett, B.S.; Stadtman, E.R. Methionine residues as endogenous antioxidants in proteins. Proc. Natl. Acad. Sci. USA 1996, 93, 15036-15040. [CrossRef]

116. Netzer, N.; Goodenbour, J.M.; David, A.; Dittmar, K.A.; Jones, R.B.; Schneider, J.R.; Boone, D.; Eves, E.M.; Rosner, M.R.; Gibbs, J.S.; et al. Innate immune and chemically triggered oxidative stress modifies translational fidelity. Nature 2009, 462, 522-526. [CrossRef]

117. Lee, J.Y.; Kim, D.G.; Kim, B.-G.; Yang, W.S.; Hong, J.; Kang, T.; Oh, Y.S.; Kim, K.R.; Han, B.W.; Hwang, B.J.; et al. Promiscuous methionyl-tRNA synthetase mediates adaptive mistranslation to protect cells against oxidative stress. J. Cell Sci. 2014, 127, 4234-4245. [CrossRef] [PubMed]

118. Aledo, J.C.; Li, Y.; de Magalhães, J.P.; Ruíz-Camacho, M.; Pérez-Claros, J.A. Mitochondrially encoded methionine is inversely related to longevity in mammals. Aging Cell 2011, 10, 198-207. [CrossRef] [PubMed]

119. Drazic, A.; Miura, H.; Peschek, J.; Le, Y.; Bach, N.C.; Kriehuber, T.; Winter, J. Methionine oxidation activates a transcription factor in response to oxidative stress. Proc. Natl. Acad. Sci. USA 2013, 110, 9493-9498. [CrossRef]

120. Gallmetzer, A.; Silvestrini, L.; Schinko, T.; Gesslbauer, B.; Hortschansky, P.; Dattenböck, C.; Muro-Pastor, M.I.; Kungl, A.; Brakhage, A.A.; Scazzocchio, C.; et al. Reversible oxidation of a conserved methionine in the nuclear export sequence determines subcellular distribution and activity of the fungal nitrate regulator NirA. PLoS Genet. 2015, 11, e1008527. [CrossRef]

121. Hung, R.; Spaeth, C.S.; Yesilyurt, H.G.; Terman, J.R. SelR reverses Mical-mediated oxidation of actin to regulate F-actin dynamics. Nat. Cell Biol. 2013, 15, 1445-1454. [CrossRef] [PubMed]

122. Lee, B.C.; Péterfi, Z.; Hoffmann, F.W.; Moore, R.E.; Kaya, A.; Avanesov, A.; Lee, B.C.; Tarrago, L.; Zhou, Y.; Weerapana, E.; et al. MsrB1 and MICALs regulate actin assembly and macrophage function via reversible stereoselective methionine oxidation. Mol. Cell 2013, 51, 397-404. [CrossRef] [PubMed]

123. Hung, R.-J.; Park, C.W.; Terman, J.R. Direct redox regulation of F-actin assembly and disassembly by Mical. Science 2011, 334, 1710-1714. [CrossRef] [PubMed]

124. Erickson, J.R.; Joiner, M.A.; Guan, X.; Kutschke, W.; Yang, J.; Oddis, C.V.; Bartlett, R.K.; Lowe, J.S.; Donnell, S.E.O.; Aykin-burns, N.; et al. A dynamic pathway for calcium-Independent activation of CaMKII by methionine oxidation. Cell 2008, 133, $462-474$. [CrossRef] [PubMed]

125. Konstantinidis, K.; Bezzerides, V.J.; Lai, L.; Isbell, H.M.; Wei, A.C.; Wu, Y.; Viswanathan, M.C.; Blum, I.D.; Granger, J.M.; Heims-Waldron, D.; et al. MICAL1 constrains cardiac stress responses and protects against disease by oxidizing CaMKII. J. Clin. Investig. 2020, 130, 4663-4678. [CrossRef]

126. Lewis, A.K.; Dunleavy, K.M.; Senkow, T.L.; Her, C.; Horn, B.T.; Jersett, M.A.; Mahling, R.; McCarthy, M.R.; Perell, G.T.; Valley, C.C.; et al. Oxidation increases the strength of the methionine-aromatic interaction. Nat. Chem. Biol. 2016, 12, 860-866. [CrossRef]

127. Valverde, H.; Cantón, F.R.; Aledo, J.C. MetOSite: An integrated resource for the study of methionine residues sulfoxidation. Bioinformatics 2019, 35, 4849-4850. [CrossRef]

128. Yang, Y.S.; Kato, M.; Wu, X.; Litsios, A.; Sutter, B.M.; Wang, Y.; Hsu, C.H.; Wood, N.E.; Lemoff, A.; Mirzaei, H.; et al. Yeast Ataxin-2 Forms an Intracellular Condensate Required for the Inhibition of TORC1 Signaling during Respiratory Growth. Cell 2019, 177, 697-710.e17. [CrossRef] [PubMed]

129. Aledo, J.C. Methionine in proteins: The Cinderella of the proteinogenic amino acids. Protein Sci. 2019, 28, 1785-1796. [CrossRef]

130. Gellman, S.H. On the role of methionine residues in the sequence-independent recognition of nonpolar protein surfaces. Biochemistry 1991, 30, 6633-6636. [CrossRef] [PubMed]

131. Janin, J.; Wodak, S. Conformation of amino acid side-chains in proteins. J. Mol. Biol. 1978, 125, 357-386. [CrossRef]

132. Zauhar, R.J.; Colbert, C.L.; Morgan, R.S.; Welsh, W.J. Evidence for a strong sulfur-aromatic interaction derived from crystallographic data. Biopolymers 2000, 53, 233-248. [CrossRef]

133. Reid, C.; Lindley, P.F.; Thornton, J.M. Sulphur-aromatic interaction in proteins. FEBS Lett. 1985, 190, 209-213. [CrossRef]

134. Morgan, R.S.; Tatsch, C.E.; Gushard, R.H.; Mcadon, J.M.; Warme, P.K. Chains of alternating sulfur and П-bonded atoms in eight small proteins. Int. J. Pept. Protein Res. 1978, 11, 209-217. [CrossRef]

135. Aledo, J.C. ptm: An R package for the study of methionine sulfoxidation and other posttranslational modifications. Bioinformatics 2021, btab348. [CrossRef] [PubMed]

136. Orabi, E.A.; English, A.M. Modeling protein S-aromatic motifs reveals their structural and redox flexibility. J. Phys. Chem. B 2018, 122, 3760-3770. [CrossRef]

137. Orabi, E.A.; English, A.M. Predicting structural and energetic changes in Met-aromatic motifs on methionine oxidation to the sulfoxide and sulfone. Phys. Chem. Chem. Phys. 2018, 20, 23132-23141. [CrossRef]

138. Lim, J.C.; Kim, G.; Levine, R.L. Stereospecific oxidation of calmodulin by methionine sulfoxide reductase A. Free Radic. Biol. Med. 2013, 61, 257-264. [CrossRef] [PubMed]

139. Marimoutou, M.; Springer, D.A.; Liu, C.; Kim, G.; Levine, R.L. Oxidation of methionine 77 in calmodulin alters mouse growth and behavior. Antioxidants 2018, 7, 140. [CrossRef] [PubMed]

140. Aledo, J.C.; Aledo, P. Susceptibility of protein methionine oxidation in response to hydrogen peroxide treatment-ex vivo versus in vitro: A computational insight. Antioxidants 2020, 9, 987. [CrossRef]

141. Veredas, F.J.; Cantón, F.R.; Aledo, J.C. Methionine residues around phosphorylation sites are preferentially oxidized in vivo under stress conditions. Sci. Rep. 2017, 7, 40403. [CrossRef] 
142. Zhang, X.H.; Weissbach, H. Origin and evolution of the protein-repairing enzymes methionine sulphoxide reductases. Biol. Rev. 2008, 83, 249-257. [CrossRef]

143. Aledo, J.C. Inferring Methionine Sulfoxidation and serine Phosphorylation crosstalk from Phylogenetic analyses. BMC Evol. Biol. 2017, 17, 171. [CrossRef]

144. Black, S.D.; Mould, D.R. Development of hydrophobicity parameters to analyze proteins which bear post- or cotranslational modifications. Anal. Biochem. 1991, 193, 72-82. [CrossRef]

145. Bigelow, D.J.; Squier, T.C. Thioredoxin-dependent redox regulation of cellular signaling and stress response through reversible oxidation of methionines. Mol. Biosyst. 2011, 7, 2101-2109. [CrossRef]

146. Wong, Y.Q.; Binger, K.J.; Howlett, G.J.; Griffin, M.D.W. Methionine oxidation induces amyloid fibril formation by full-length apolipoprotein A-I. Proc. Natl. Acad. Sci. USA 2010, 107, 1977-1982. [CrossRef] [PubMed]

147. Walker, E.J.; Bettinger, J.Q.; Welle, K.A.; Hryhorenko, J.R.; Ghaemmaghami, S. Global analysis of methionine oxidation provides a census of folding stabilities for the human proteome. Proc. Natl. Acad. Sci. USA 2019, 116, 6081-6090. [CrossRef] [PubMed]

148. Bhardwaj, A.; Myers, M.P.; Buratti, E.; Baralle, F.E. Characterizing TDP-43 interaction with its RNA targets. Nucleic Acids Res. 2013, 41, 5062-5074. [CrossRef] [PubMed]

149. Chu, J.F.; Majumder, P.; Chatterjee, B.; Huang, S.L.; Shen, C.K.J. TDP-43 Regulates Coupled Dendritic mRNA Transport-Translation Processes in Co-operation with FMRP and Staufen1. Cell Rep. 2019, 29, 3118-3133.e6. [CrossRef] [PubMed]

150. Chang, C.K.; Wu, T.H.; Wu, C.Y.; Chiang, M.H.; Toh, E.K.W.; Hsu, Y.C.; Lin, K.F.; Liao, Y.H.; Huang, T.H.; Huang, J.J.T. The $\mathrm{N}$-terminus of TDP-43 promotes its oligomerization and enhances DNA binding affinity. Biochem. Biophys. Res. Commun. 2012, 425, 219-224. [CrossRef]

151. Mompeán, M.; Romano, V.; Pantoja-Uceda, D.; Stuani, C.; Baralle, F.E.; Buratti, E.; Laurents, D.V. The TDP-43 N-terminal domain structure at high resolution. FEBS J. 2016, 283, 1242-1260. [CrossRef]

152. Bolognesi, B.; Faure, A.J.; Seuma, M.; Schmiedel, J.M.; Tartaglia, G.G.; Lehner, B. The mutational landscape of a prion-like domain. Nat. Commun. 2019, 10, 4162. [CrossRef]

153. Buratti, E. Functional Significance of TDP-43 Mutations in Disease. Adv. Genet. 2015, 91, 1-53. [CrossRef]

154. Bentmann, E.; Neumann, M.; Tahirovic, S.; Rodde, R.; Dormann, D.; Haass, C. Requirements for stress granule recruitment of fused in sarcoma (FUS) and TAR DNA-binding protein of 43 kDa (TDP-43). J. Biol. Chem. 2012, 287, 23079-23094. [CrossRef]

155. Saini, A.; Chauhan, V.S. Delineation of the core aggregation sequences of TDP-43 C-terminal fragment. ChemBioChem 2011, 12, 2495-2501. [CrossRef] [PubMed]

156. Lancaster, A.K.; Nutter-Upham, A.; Lindquist, S.; King, O.D. PLAAC: A web and command-line application to identify proteins with prion-like amino acid composition. Bioinformatics 2014, 30, 2501-2502. [CrossRef] [PubMed]

157. Franzmann, T.M.; Alberti, S. Prion-like low-complexity sequences: Key regulators of protein solubility and phase behavior. J. Biol. Chem. 2019, 294, 7128-7136. [CrossRef] [PubMed]

158. Conicella, A.E.; Zerze, G.H.; Mittal, J.; Fawzi, N.L. ALS Mutations Disrupt Phase Separation Mediated by $\alpha$-Helical Structure in the TDP-43 Low-Complexity C-Terminal Domain. Structure 2016, 24, 1537-1549. [CrossRef] [PubMed]

159. Stadman, E.; Moskovitz, J.; Berlett, B.; Levine, R. Cyclic oxidation and reduction of protein methionine residues is an important antioxidant mechanism. Mol. Cell. Biochem. 2002, 234/235, 3-9. [CrossRef]

160. Bettinger, J.Q.; Welle, K.A.; Hryhorenko, J.R.; Ghaemmaghami, S. Quantitative Analysis of in Vivo Methionine Oxidation of the Human Proteome. J. Proteome Res. 2020, 19, 624-633. [CrossRef]

161. Cao, Q.; Boyer, D.R.; Sawaya, M.R.; Ge, P.; Eisenberg, D.S. Cryo-EM structures of four polymorphic TDP-43 amyloid cores. Nat. Struct. Mol. Biol. 2019, 26, 619-627. [CrossRef] [PubMed]

162. Xu, K.N.; Uversky, V..; Xue, B. Local Flexibility Facilitates Oxidization of Buried Methionine Residues. Protein Pept. Lett. 2012, 19, 688-697. [CrossRef]

163. Ostrowski, L.A.; Hall, A.C.; Mekhail, K. Ataxin-2: From RNA Control to Human Health and Disease. Genes 2017, 8, 157. [CrossRef]

164. Jiménez-López, D.; Guzmán, P. Insights into the evolution and domain structure of ataxin-2 proteins across eukaryotes. BMC Res. Notes 2014, 7, 1-12. [CrossRef] [PubMed]

165. Albrecht, M.; Golatta, M.; Wüllner, U.; Lengauer, T. Structural and functional analysis of ataxin-2 and ataxin-3. Eur. J. Biochem. 2004, 271, 3155-3170. [CrossRef]

166. Mangus, D.A.; Amrani, N.; Jacobson, A. Pbp1p, a Factor Interacting with Saccharomyces cerevisiae Poly(A)-Binding Protein, Regulates Polyadenylation. Mol. Cell. Biol. 1998, 18, 7383-7396. [CrossRef] [PubMed]

167. Bakthavachalu, B.; Huelsmeier, J.; Sudhakaran, I.P.; Hillebrand, J.; Singh, A.; Petrauskas, A.; Thiagarajan, D.; Sankaranarayanan, M.; Mizoue, L.; Anderson, E.N.; et al. RNP-Granule Assembly via Ataxin-2 Disordered Domains Is Required for Long-Term Memory and Neurodegeneration. Neuron 2018, 98, 754-766.e4. [CrossRef]

168. Rabanal-Ruiz, Y.; Korolchuk, V.I. mTORC1 and nutrient homeostasis: The central role of the lysosome. Int. J. Mol. Sci. 2018, 19, 818. [CrossRef]

169. Takahara, T.; Maeda, T. Transient Sequestration of TORC1 into Stress Granules during Heat Stress. Mol. Cell 2012, 47, $242-252$. [CrossRef]

170. Düster, R.; Kaltheuner, I.H.; Schmitz, M.; Geyer, M. 1,6-Hexanediol, commonly used to dissolve liquid-liquid phase separated condensates, directly impairs kinase and phosphatase activities. J. Biol. Chem. 2021, 296, 100260. [CrossRef] 
171. Marcotte, E.M.; Pellegrini, M.; Yeates, T.O.; Eisenberg, D. A census of protein repeats. J. Mol. Biol. 1999, 293, 151-160. [CrossRef] [PubMed]

172. Haerty, W.; Brian Golding, G. Low-complexity sequences and single amino acid repeats: Not just "junk" peptide sequences. Genome 2010, 53, 753-762. [CrossRef] [PubMed]

173. Ghesquière, B.; Jonckheere, V.; Colaert, N.; Van Durme, J.; Timmerman, E.; Goethals, M.; Schymkowitz, J.; Rousseau, F.; Vandekerckhove, J.; Gevaert, K. Redox proteomics of protein-bound methionine oxidation. Mol. Cell. Proteom. 2011, 10, M110.006866. [CrossRef]

174. Ochoa, D.; Pazos, F. Practical aspects of protein co-evolution. Front. Cell Dev. Biol. 2014, 2, 1-9. [CrossRef]

175. Shenton, D.; Smirnova, J.B.; Selley, J.N.; Carroll, K.; Hubbard, S.J.; Pavitt, G.D.; Ashe, M.P.; Grant, C.M. Global translational responses to oxidative stress impact upon multiple levels of protein synthesis. J. Biol. Chem. 2006, 281, 29011-29021. [CrossRef] [PubMed]

176. Bonnal, S.; Boutonnet, C.; Prado-Lourence, L.; Vagner, S. IRESdb: The internal ribosome entry site database. Nucleic Acids Res. 2003, 31, 427-428. [CrossRef] [PubMed]

177. Wang, X.; Pan, T. Methionine mistranslation bypasses the restraint of the genetic code to generate mutant proteins with distinct activities. PLoS Genet. 2015, 11, e1005745. [CrossRef]

178. Wiltrout, E.; Goodenbour, J.M.; Fréchin, M.; Pan, T. Misacylation of tRNA with methionine in Saccharomyces cerevisiae. Nucleic Acids Res. 2012, 40, 10494-10506. [CrossRef] [PubMed]

179. Luo, S.; Levine, R.L. Methionine in proteins defends against oxidative stress. FASEB J. 2009, 23, 464-472. [CrossRef] [PubMed]

180. Jones, T.E.; Alexander, R.W.; Pan, T. Misacylation of specific nonmethionyl tRNAs by a bacterial methionyl-tRNA synthetase. Proc. Natl. Acad. Sci. USA 2011, 108, 6933-6938. [CrossRef]

181. Khan, N.A.; Nikkanen, J.; Yatsuga, S.; Jackson, C.; Wang, L.; Pradhan, S.; Kivelä, R.; Pessia, A.; Velagapudi, V.; Suomalainen, A. mTORC1 Regulates Mitochondrial Integrated Stress Response and Mitochondrial Myopathy Progression. Cell Metab. 2017, 26, 419-428.e5. [CrossRef]

182. Ma, X.; Jin, M.; Cai, Y.; Xia, H.; Long, K.; Liu, J.; Yu, Q.; Yuan, J. Mitochondrial Electron Transport Chain Complex III Is Required for Antimycin A to Inhibit Autophagy. Chem. Biol. 2011, 18, 1474-1481. [CrossRef]

183. D'Autréaux, B.; Toledano, M.B. ROS as signalling molecules: Mechanisms that generate specificity in ROS homeostasis. Nat. Rev. Mol. Cell Biol. 2007, 8, 813-824. [CrossRef]

184. Cabiscol, E.; Piulats, E.; Echave, P.; Herrero, E.; Ros, J. Oxidative Stress Promotes Specific Protein Damage inSaccharomyces cerevisiae. J. Biol. Chem. 2000, 275, 27393-27398. [CrossRef]

185. Maslanka, R.; Zadrag-Tecza, R.; Kwolek-Mirek, M. Linkage between carbon metabolism, redox status and cellular physiology in the yeast saccharomyces cerevisiae devoid of SOD1 or SOD2 gene. Genes 2020, 11, 780. [CrossRef] [PubMed]

186. Kaludercic, N.; Deshwal, S.; Di Lisa, F. Reactive oxygen species and redox compartmentalization. Front. Physiol. $2014,5,285$. [CrossRef]

187. Aledo, J.C. Life-history constraints on the mechanisms that control the rate of ROS production. Curr. Genom. 2014, 15, 217-230. [CrossRef]

188. Fang, J.; Beattie, D.S. External alternative NADH dehydrogenase of Saccharomyces cerevisiae: A potential source of superoxide. Free Radic. Biol. Med. 2003, 34, 478-488. [CrossRef]

189. Herrero, E.; Ros, J.; Bellí, G.; Cabiscol, E. Redox control and oxidative stress in yeast cells. Biochim. Biophys. Acta Gen. Subj. 2008, 1780, 1217-1235. [CrossRef]

190. Overkamp, K.M.; Bakker, B.M.; Kötter, P.; Van Tuijl, A.; De Vries, S.; Van Dijken, J.P.; Pronk, J.T. In vivo analysis of the mechanisms for oxidation of cytosolic NADH by Saccharomyces cerevisiae mitochondria. J. Bacteriol. 2000, 182, 2823-2830. [CrossRef]

191. Weber, M.; Basu, S.; González, B.; Greslehner, G.P.; Singer, S.; Haskova, D.; Hasek, J.; Breitenbach, M.; Gourlay, C.W.; Cullen, P.J.; et al. Actin cytoskeleton regulation by the yeast nadph oxidase yno1p impacts processes controlled by mapk pathways. Antioxidants 2021, 10, 322. [CrossRef] [PubMed]

192. Elfarra, A.A.; Krause, R.J. Potential roles of flavin-containing monooxygenases in sulfoxidation reactions of L-methionine, N-acetyl-L-methionine and peptides containing L-methionine. Biochim. Biophys. Acta Proteins Proteom. 2005, 1703, 183-189. [CrossRef] [PubMed]

193. Manta, B.; Gladyshev, V.N. Regulated methionine oxidation by monooxygenases. Free Radic. Biol. Med. 2017, 109, 141-155. [CrossRef] [PubMed]

194. Suh, J.K.; Poulsen, L.L.; Ziegler, D.M.; Robertus, J.D. Molecular cloning and kinetic characterization of a flavin-containing monooxygenase from Saccharomyces cerevisiae. Arch. Biochem. Biophys. 1996, 336, 268-274. [CrossRef] [PubMed]

195. Sharov, V.S.; Schöneich, C. Diastereoselective protein methionine oxidation by reactive oxygen species and diastereoselective repair by methionine sulfoxide reductase. Free Radic. Biol. Med. 2000, 29, 986-994. [CrossRef]

196. Delaye, L.; Becerra, A.; Orgel, L.; Lazcano, A. Molecular evolution of peptide methionine sulfoxide reductases (MsrA and MsrB): On the early development of a mechanism that protects against oxidative damage. J. Mol. Evol. 2007, 64, 15-32. [CrossRef]

197. Kaya, A.; Koc, A.; Lee, B.C.; Fomenko, D.E.; Rederstorff, M.; Krol, A.; Lescure, A.; Gladyshev, V.N. Compartmentalization and regulation of mitochondrial function by methionine sulfoxide reductases in yeast. Biochemistry 2010, 49, 8618-8625. [CrossRef] [PubMed] 